For Publication in Ocean Engineering

\title{
Methods for determining the optimal arrangement of water deluge systems on offshore installations
}

\author{
Sang Jin Kim ${ }^{1,2}$, Dong Hun Lee ${ }^{1,2}$, Hye Min Hong ${ }^{1,2}$, Se Hee Ahn ${ }^{1,2}$, Jeong Beom Park ${ }^{1,2}$, Jung \\ Kwan Seo ${ }^{2 *}$, Bong Ju Kim², and Jeom Kee Paik ${ }^{1,2,3}$ \\ ${ }^{1}$ Department of Naval Architecture and Ocean Engineering, Pusan National University, Busan, \\ Korea \\ ${ }^{2}$ The Korea Ship and Offshore Research Institute (The Lloyd's Register Foundation Research \\ Centre of Excellence), Pusan National University, Busan, Republic of Korea \\ ${ }^{3}$ Department of Mechanical Engineering, University College London, London, Korea
}

\begin{abstract}
Offshore installations are prone to fire and/or explosion accidents. Fires have particularly serious consequences due to their high temperatures and heat flux, which affect humans, structures and environments alike. Due to the hydrocarbon explosions caused by delayed ignition following gas dispersion, fires can be the result of immediate ignition after gas release. Accordingly, it can be difficult to decrease their frequency, which is an element of risk (risk = frequency $\mathrm{x}$ consequence), using an active protection system (APS) such as gas detectors capable of shutting down the operation. Thus, it is more efficient to reduce the consequence using a passive protection system (PSS) such as water spray. It is important to decide the number and location of water deluge systems, thus the aim of this study is to introduce a new procedure for optimising the locations of water deluge systems using the water deluge location index (WLI) proposed herein. The locations of water deluge systems are thus optimised based on the results of credible fire scenarios using a three-dimensional (3D) computational fluid dynamics (CFD) tool. The effects of water spray and the effectiveness of the WLI are investigated in comparison with uniformly distributed sprays.
\end{abstract}

\section{Keywords}

* Corresponding author. Tel.: +82515102415

Email address: seojk@pusan.ac.kr 
offshore installations, fire accidents, optimisation of water deluge systems, water deluge location index (WLI)

\section{Introduction}

The operation of offshore facilities such as FPSOs, TLPs, SPARs and semi-submersibles in shallow or deep water is prone to hazardous risks. Fires and explosions account for more than $70 \%$ of accidents on offshore installations (Christou and Konstantinidou, 2012). Fires with high temperatures and heat flux result in catastrophic consequences that lead to casualties, property damage and pollution. The Piper Alpha (6 July 1998) and Deepwater Horizon (20 April 2010) accidents are typical examples of fire events (Fig. 1), and numerous fire accidents have been reported on offshore installations (Christou and Konstantinidou, 2012).

To prevent fire accidents and/or reduce their consequences, the importance of fire risk assessment and management has been magnified (Czujko and Paik, 2012a, 2012b). The risk assessment and management of fire are noted in the rules, recommended practices and design guidelines (Spouge, 1999; NORSOK, 2010; ABS, 2014; LR, 2014) and relevant guidelines have been established accordingly (Nolan, 1996; Walker et al., 2003; Vinnem, 2007; Paik and Czujko, 2009, 2010, 2011, 2012; Paik et al., 2011). The risk can be defined as

$$
\text { Risk }=\text { Frequency } \times \text { Consequence } .
$$

The two most commonly implemented risk control options are active protection systems (APSs) and passive protection systems (PPSs). APSs such as gas detectors and showdown systems are used to prevent accidents and PPSs such as water sprays, heat shields, fire and blast walls and passive fire protection (PFP) are used to address the consequences after the accidents. PPSs are usually preferred over APSs due to the latter's higher cost (Lei et al., 2015; Sohn et al., 2015), and the optimal placement of protection systems also influences their cost effectiveness. 
Seo et al. (2013) introduced a methodology for optimising gas detector locations among APSs on offshore installations using a quantitative approach and a two-dimensional analytical method. Paik (2011) investigated the effects of fire walls and PFP, optimising them using quantitative fire risk assessment and management.

Although there have been numerous studies on protection systems, they have not successfully optimised the effects. Thus, the 3D CFD simulation is needed to improve the accuracy and effectiveness.

The objectives of this study are to (i) suggest a procedure to optimise water spray systems using the water deluge location index (WLI) - a new approach to selecting the optimised locations of water spray systems using the 3D CFD simulation; (ii) investigate the effects of water spray systems; and (iii) compare the proposed system with water spray systems distributed by traditional methods. Among the three types of water spray systems shown in Fig. 2, the water deluge system (Fig. 2(a)) is examined in the present study. After selecting probabilistic fire scenarios, fire CFD simulations are performed by Kameleon FireEx (KFX) CFD simulation. Then, optimised locations are suggested for water deluge systems and their performance is compared with that of uniformly distributed water sprays.

\section{A procedure for the optimisation of water deluge system locations}

Fig. 3 shows a procedure for the optimisation of water deluge system locations using the proposed WLI.

The procedure is composed of the following steps:

1) selection of credible fire scenarios;

2) fire CFD simulations and/or experimental tests;

3) obtaining the consequences of fire loads (e.g., temperature-time history, temperature distribution and temperature escalation);

4) definition of the operation temperatures for water deluge systems (e.g., reference temperatures);

5) calculation of WLI; and

6) selection of optimised water deluge locations. 
The operation (reference) temperature can be defined by the rule, international standard, recommended practice and/or designer. For example, the National Fire Protection Association (NFPA, 1996) suggests that the operation temperature of water spray should be lower than $121^{\circ} \mathrm{C}$. Designers can also suggest that the reference temperature be lower than the 'as low as reasonably practical' (ALARP) temperature.

\section{Introducing the water deluge location index (WLI)}

In this study, a ranking index - the WLI - is proposed for use in selecting optimised locations for water deluge systems. The WLI rates each space, and can be calculated as

$$
\mathrm{WLI}_{\mathrm{i}}=\left[\sum_{\mathrm{n}=1}^{\mathrm{N}} \frac{\left(\mathrm{T}_{\mathrm{R}, \mathrm{n}}-\mathrm{T}_{\mathrm{r}}\right) / \mathrm{t}_{\mathrm{R}, \mathrm{n}}}{\mathrm{N}}\right] \times \frac{\mathrm{F}}{\mathrm{N}}, \quad(\mathrm{i}=1,2,3, \cdots, \text { total number of spaces }),
$$

where $\left(T_{R, n}-T_{r}\right) / t_{R, n}$ is the slope of the temperature until the reference temperature is reached, $T_{R}$ is the reference temperature, $T_{r}$ is the room temperature, $t_{R}$ is the time at which the reference temperature is reached, $\mathrm{n}$ is the scenario number, $\mathrm{N}$ is the total number of scenarios and $\mathrm{F}$ is the number of scenarios that detect a temperature above the reference temperature. If a scenario does not have a temperature above the reference temperature, the slope $\left(\left(T_{R, n}-T_{r}\right) / t_{R, n}\right)$ will be zero.

The WLI ratings can be obtained through the following steps:

1) definition of the reference temperature at which the water sprays operate (by rules, recommended practices, standards, etc.);

2) investigation of the time for each scenario at the reference temperature;

3) calculation of a slope of each space;

4) calculation of cumulative frequency for each space; and

5) generation of WLI in entire domain using Eq. (2).

Fig. 4 illustrates an example of spaces and temperature distribution at specific times to calculate the WLI. The size of each space (A1, A2-F5) should not exceed the capacity (i.e., radius) of the water sprays. The WLI is calculated by considering the temperature and time at each space. 
Fig. 5 presents an example of nine optimised water deluge system locations obtained by the WLI in two fire scenarios.

\section{Applied example of the WLI}

\subsection{Target structure}

A hypothetical floating liquefied natural gas (FLNG) topside structure constructed by the Korea Ship and Offshore Research Institute (KOSORI) at Pusan National University was selected as the target structure to perform an applied example. It consists of three decks: the upper (solid), mezzanine ( 0.7 porosity) and process (solid), as shown in Fig. 6.

\subsection{Selection of fire scenarios}

It is important to select credible fire scenarios when making decisions about optimised water spray positions. There are numerous methods for selecting such scenarios, including standard random, stratified, Monte Carlo simulations (MCSs) and Latin hypercube samplings (LHSs) (Czujko, 2001). Among those, the LHSs use a probability density function for each variable that generates probabilistic scenarios with variable combinations. In this study, an LHS is used to select the fire scenarios because it can efficiently represent each whole scenario with a probabilistic approach. Moreover, it can cover all possible values even if they have very small probabilities.

Fig. 7 presents the scheme of the LHS technique (Ye, 1998) for selecting the fire scenarios. The LHS uses each variable value only once, and the values do not overlap, thus each variable's representative value takes the centre of the section.

Fig. 8 presents the probability density functions of the environmental and operation parameters for the LHS. Table 1 shows the 30 selected fire scenarios using the sampling technique with parameters.

\subsection{Fire CFD simulations}


To analyse the fire CFD simulations, the KFX (2013) CFD tool is used. Fig. 9 shows the target structure modelled in KFX and the extent of the analysis, which is a simulation volume. In this study, the modelling technique developed by Lee et al. (2014) is applied to the KFX simulations.

\subsubsection{Grid convergence study}

To achieve accurate and effective simulations, the grid convergence study is essential. Table 2 presents three cases with gird convergence models. All three cases have a 109×210 (mm) grid cell around the leak positions. Fig. 10 shows the results of the grid convergence study. Cases 1 and 2 show similar results, with

the former having the finest grid size in the present study. Thus, the grid for case 2 is used in the CFD simulations.

\subsubsection{Obtaining the fire loads in spaces for calculating the WLI}

Three elevations between the decks are selected to locate the monitoring points, and the points are equally spaced to obtain the fire loads, as shown in Fig. 11. The fire loads obtained from these points are then used as the fire loads in spaces for calculating the WLI.

To calculate the WLI of each space, the districts must be divided along the spaces, as shown in Fig. 12. In this study, water sprays with a radius of $2.0 \mathrm{~m}$ are assumed to define the space. The average fire loads at the monitoring points in each space are applied to investigate the WLI.

\subsection{Results of CFD simulations}

From the simulations with 30 fire scenarios, 30 temperature distributions are obtained for each space. Fig. 13 provides examples of temperature-time histories resulting from the analysis of two spaces. Each space has different fire load characteristics, which allows the spaces to be ranked.

Fig. 14 provides examples of the temperature distributions for four fire scenarios at $2 \mathrm{~m}$ of elevation, 60 $\mathrm{s}$ after ignition. It illustrates the concept of WLI and the locations of high temperatures in each scenario. 
The WLI considers a temperature at all of the time steps, although the distribution in Fig. 14 indicates specific times.

\subsection{Optimisation of water deluge system locations}

\subsubsection{The WLI}

To select optimised water deluge system locations, it is necessary to calculate the WLI developed in this study. Fig. 15 presents the temperature-time histories (shown in Fig. 13) with reference temperatures; specifically, $121^{\circ} \mathrm{C}$ (as suggested by the NFPA (1996)) and $500^{\circ} \mathrm{C}$, for example. The averages of the slopes in all of the spaces are calculated using Eq. (2) with a reference temperature. For example, scenarios 7 and 9 have an average slope in space $\mathrm{B} 3$ with a $500^{\circ} \mathrm{C}$ reference temperature, whereas scenarios 10, 11, 12 and 26 have no score because the temperatures of scenarios 10,11 and 12 do not reach the reference temperature. In contrast, scenarios 7, 9 and 10 have scores in space $\mathrm{B} 3$ with a $121^{\circ} \mathrm{C}$ reference temperature.

Figs. 16 and 17 show the average slopes in all of the spaces calculated using Eq. (2) with $121^{\circ} \mathrm{C}$ and $500^{\circ} \mathrm{C}$ as the reference temperatures. The slopes of 30 temperature-time histories at each space were averaged, and the scores for the average slopes were extremely different, based on the reference temperatures.

Another important factor in calculating the WLI is how frequently the temperature exceeds the reference temperature. In Fig. 18, the frequencies for the spaces are $3(\mathrm{~B} 3)$ and $3(\mathrm{H} 3)$ with a $121^{\circ} \mathrm{C}$ reference temperature, considering only 6 scenarios in the figure. The frequencies for a $500^{\circ} \mathrm{C}$ reference temperature are $2(\mathrm{~B} 3)$ and $0(\mathrm{H} 3)$.

Figs. 18 and 19 show the frequencies for the total number of temperatures exceeding the reference temperature $\left(121^{\circ} \mathrm{C}\right.$ or $\left.500^{\circ} \mathrm{C}\right)$ in all of the spaces, considering 30 scenarios.

\subsubsection{Proposed water deluge system locations}


The WLI can be calculated using Eq. (2), which consists of the average of slopes (in Figs. 16 and 17) and frequencies (in Figs. 18 and 19). The indices can then be ranked. Table 3 shows the ranked spaces with $121^{\circ} \mathrm{C}$ and $500^{\circ} \mathrm{C}$ reference temperatures. Among them, high-ranking indices are proposed to determine the water deluge system locations.

Table 4 and Figs. 20 and 21 present the high-ranking positions and their proposed locations for $121^{\circ} \mathrm{C}$ and $500^{\circ} \mathrm{C}$ reference temperatures, assuming 9 water deluge systems. The proposed positions, based on the reference temperatures, differ from those shown in Figs. 20 and 21.

\section{Efficiency of the proposed method}

To verify the efficiency of the WLI in the present study, the uniformly distributed and optimised (by WLI) positions are compared. In this case, 9 water sprays are used. Fig. 22 shows the selected water deluge system locations obtained by the WLI, which is calculated with a $121^{\circ} \mathrm{C}$ reference temperature, as suggested by the NFPA (1996). Fig. 23 indicates the uniformly distributed water sprays.

Fig. 24 shows the comparison of the results, which are temperature distributions $40 \mathrm{~s}$ after ignition considered with and without water deluge systems by WLI and the uniform arrangement method. The operation time for the water sprays is $30 \mathrm{~s}$ after a fire.

According to the Health and Safety Executive (HSE, 2006), temperatures from $127^{\circ} \mathrm{C}$ to $203^{\circ} \mathrm{C}$ affect humans, who cannot survive exposure to temperatures above $203^{\circ} \mathrm{C}$. DNV $\cdot \mathrm{GL}$ (2008) investigated critical temperatures for structures, and the critical temperatures of structural and ordinary reinforcing steel are between $400-450^{\circ} \mathrm{C}$.

Table 5 presents the size and number of heated areas (indices) at $40 \mathrm{~s}$, which is $10 \mathrm{~s}$ after starting the water deluge systems with critical bounds of temperature suggested by the HSE (2006) and DNV.GL (2008). Fig. 25 illustrates the effects of water sprays on the number of heated areas, and reveals that the 
WLI-optimised water deluge system locations can efficiently reduce the consequences of fire loads, compared with uniform arrangement.

Fig. 26 illustrates the time-dependent heated area below $127^{\circ} \mathrm{C}$ and above $700^{\circ} \mathrm{C}$. It precisely shows the strength of WLI-optimised water deluge system locations.

\section{Concluding remarks}

The objectives of this study were to (i) suggest a new procedure for selecting efficient water deluge system locations to prevent and reduce the consequences of fire accidents on offshore installations; (ii) investigate the effects of water sprays; and (iii) compare the aforementioned results with those of the traditional method (uniformly distributed water sprays). Although the water sprays in the traditional method are uniformly located, the WLI is proposed to optimise water deluge system locations. The conclusions are as follows:

- The WLI is calculated using reference temperatures based on the operation conditions of water sprays.

- The WLI is calculated considering time-dependent temperatures.

- The WLI considers the frequency of the fire loads in each space.

- A demonstration of optimising water deluge system locations using WLI is provided with reference temperatures, and the water deluge systems are located at high-ranking indices.

- The reliability of the WLI is validated through comparison, and it is found to be more efficient than uniformly distributed systems in reducing the consequences of fire loads.

Water sprays are one method for preventing the serious damage caused by fire accidents, and for reducing the consequences of fires. The efficient placement of water deluge systems is important, as the systems are related to cost. The WLI can be helpful in optimising water deluge system locations, and it could facilitate the effective management of offshore platform risks. 


\section{Acknowledgement}

This research was financially supported by the Ministry of Trade, Industry and Energy (MOTIE) and Korea Institutes for Advancement of Technology (KIAT) through the Promoting Reginal Specialized (Grant no.: A010400243).

\section{References}

ABS, 2014. Guidance noted in fire-fighting systems. American Bureau of Shipping, Texas, USA.

Christou, M., Konstantinidou, M., 2012. Safety of offshore oil and gas operation: lessons from past accident analysis. Joint Research Centre (JRC) Scientific and Policy Reports, European Commission, Brussels, Belgium.

Czujko, J., 2001. Design of offshore facilities to resist gas explosion hazard: engineering handbook. CorrOcean ASA, Trondheim, Norway.

Czujko, J., Paik, J.K., 2012a. Hydrocarbon explosion and fire engineering - assessing and managing hydrocarbon explosion and fire risks in offshore installations. Marine Technology, pp. 23-25.

Czujko, J., Paik, J.K., 2012b. Paradigm change in safety design against hydrocarbon explosions and fires. FABIG Newsletter (60), 20-38.

DNV·GL, 2008. DNV-OS-D301: Fire protection, Det Norske Veritas, Oslo, Norway.

HSE, 2006. Methods of approximation and determination of human vulnerability for offshore major accident hazard assessment. Health and Safety Executive, London, UK.

KFX, 2013. User's manual for Kameleon Fire EX. Computational Industry Technologies AS, Stavanger, Norway.

Lee, D.H., Kim, J.H., Hong, H.M., Kim, B.J., Paik, J.K., Park, S.I., Heo, T.U., 2014. An investigation on heat reduction effect of water spray nozzle used for flare system thought comparison between the experiment and CFD simulation. In: Proceedings of the 7th International Conference on Thin-walled Structures, Busan, Korea. 
Lei, H.Y., Lee, J.C., Li, C.B., Ha, Y.C., Seo, J.K., Kim, B.J., Paik, J.K., 2015. Cost-benefit analysis of corrugated blast walls. Ships and Offshore Structures 10(5), 565-574.

LR, 2014. Rules and regulations for the classification of offshore units - guidelines for the calculation of probabilistic explosion loads. Lloyd's Register, Southampton, UK.

NFPA, 1996. NFPA-15: Standard for water spray fixed systems for fire protection. National Fire Protection Association, Massachusetts, USA.

Nolan, D.P., 1996. Handbook of fire and explosion protection engineering principles for oil, gas, chemical, and related facilities. Noyes Publications, New Jersey, USA.

NORSOK, 2010. NORSOK Standard Z-013: Risk and emergency preparedness assessment. 3rd Edition. NORSOK, Oslo, Norway.

Paik, J.K., 2011. Report No. EFEF-04: Explosion and fire engineering of FPSOs (Phase III): nonlinear structural consequence analysis. The Korea Ship and Offshore Research Institute, Pusan National University, Busan, Korea.

Paik, J.K., Czujko, J., 2009. Report No. EFEF-01: Explosion and fire engineering of FPSOs (Phase I): feasibility study with literature review. The Korea Ship and Offshore Research Institute, Pusan National University, Busan, Korea.

Paik, J.K., Czujko, J., 2010. Report No. EFEF-03: Explosion and fire engineering of FPSOs (Phase II): definition of design explosion and fire loads. The Korea Ship and Offshore Research Institute, Pusan National University, Busan, Korea.

Paik, J.K., Czujko, J., 2011. Assessment of hydrocarbon explosion and fire risks in offshore installations: recent advances and future trends. The IES Journal Part A: Civil \& Structural Engineering 4(3), 167179.

Paik, J.K., Czujko, J., 2012. Engineering and design disciplines associated with hydrocarbon explosion and fire risks in offshore oil and gas facilities. Transactions of the Society of Naval Architects and Marine Engineers 120, 1-39. 
Paik, J.K., Czujko, J., Kim, B.J., Seo, J.K., Ryu, H.S., Ha, Y.C., Janiszewski, P., Musial, B., 2011. Quantitative assessment of hydrocarbon explosion and fire risks in offshore installations. Mar. Struct. 24, 73-96.

Seo, J.K., Kim, D.C., Ha, Y.C., Kim, B.J., Paik, J.K., 2013. A methodology for determining efficient gas detector locations on offshore installations. Ships and Offshore Structures 8(5), 524-535.

Sohn, J.M., Kim, S.J., Seo, J.K., Kim, B.J., Paik, J.K., 2015. Strength assessment of stiffened blast walls in offshore installations under explosions. Ship and Offshore Structures (Online available). http://dx.doi.org/10.1080/17445302.2015.1035164

Spouge, J., 1999. A guide to quantitative risk assessment for offshore installations. DNV Technica, Oslo, Norway.

Vinnem, J.E., 2007. Offshore risk assessment - principles, modelling and application of QRA studies. Springer, Stavanger, Norway.

Walker, S., Bleach, R., Carney, S., Fairlie, G., Louca, L.A., 2003. New guidance on the design of offshore structures to resist the explosion hazard. In: Proceedings of the 32nd International Conference on Ocean, Offshore and Arctic Engineering, Cancun, Mexico.

Ye, K.Q., 1998. Orthogonal column Latin hypercubes and their application in computer experiment. Journal of the American Statistical Association 93(444), 1430-1439. 


\section{Tables and Figures}

Table 1 Selected fire scenarios using the LHS technique with parameters.

\begin{tabular}{|c|c|c|c|c|c|c|c|}
\hline & $\begin{array}{c}\text { Wind direction } \\
\text { (deg.) }\end{array}$ & $\begin{array}{l}\text { Wind speed } \\
(\mathrm{m} / \mathrm{s})\end{array}$ & $\begin{array}{c}\text { Leak position } \\
\mathrm{X}(\mathrm{m})\end{array}$ & $\begin{array}{l}\text { Leak position } \\
\text { Y (m) }\end{array}$ & $\begin{array}{c}\text { Leak position } \\
\mathrm{Z}(\mathrm{m})\end{array}$ & Leak direction & $\begin{array}{c}\text { Leak rate } \\
(\mathrm{kg} / \mathrm{s})\end{array}$ \\
\hline Scenario1 & 38.39 & 4.36 & 14.38 & 9.08 & 1.11 & $-Y$ & 0.91 \\
\hline Scenario2 & 258.68 & 3.25 & 14.66 & 6.31 & 1.28 & $-Y$ & 0.26 \\
\hline Scenario3 & 83.04 & 2.53 & 17.28 & 3.28 & 2.39 & $+Y$ & 4.03 \\
\hline Scenario4 & 203.69 & 4.18 & 4.45 & 3.48 & 6.16 & $+\mathrm{Z}$ & 0.22 \\
\hline Scenario5 & 70.46 & 1.30 & 3.43 & 11.51 & 1.67 & $+\mathrm{Y}$ & 0.23 \\
\hline Scenario6 & 229.12 & 3.11 & 8.78 & 5.05 & 3.40 & $-Z$ & 0.01 \\
\hline Scenario7 & 104.65 & 4.55 & 5.14 & 4.11 & 1.01 & $+\mathrm{Z}$ & 12.00 \\
\hline Scenario8 & 270.25 & 7.64 & 3.76 & 4.67 & 7.01 & $-\mathrm{X}$ & 0.23 \\
\hline Scenario9 & 298.41 & 5.55 & 1.82 & 7.50 & 6.16 & $-Z$ & 0.82 \\
\hline Scenario10 & 195.67 & 5.94 & 3.43 & 9.11 & 1.67 & $-Y$ & 9.73 \\
\hline Scenario11 & 248.14 & 4.01 & 7.40 & 7.60 & 5.24 & $-\mathrm{X}$ & 0.73 \\
\hline Scenario12 & 172.22 & 2.97 & 5.26 & 4.67 & 6.00 & $+\mathrm{X}$ & 2.05 \\
\hline Scenario13 & 164.42 & 6.47 & 5.62 & 3.92 & 6.03 & $+Y$ & 0.11 \\
\hline Scenario14 & 148.60 & 2.68 & 7.26 & 6.26 & 1.47 & $-Y$ & 0.57 \\
\hline Scenario15 & 211.88 & 3.70 & 5.13 & 8.04 & 5.39 & $+X$ & 0.66 \\
\hline Scenario16 & 123.38 & 5.25 & 0.55 & 7.60 & 2.01 & $+\mathrm{X}$ & 0.08 \\
\hline Scenario17 & 132.07 & 3.55 & 14.10 & 6.52 & 1.28 & $+X$ & 1.13 \\
\hline Scenario18 & 15.08 & 3.85 & 15.52 & 3.41 & 1.37 & $+\mathrm{Z}$ & 0.04 \\
\hline Scenario19 & 283.26 & 0.58 & 14.66 & 6.31 & 1.28 & $+Y$ & 5.38 \\
\hline Scenario20 & 187.79 & 2.82 & 14.38 & 9.08 & 1.11 & $-Y$ & 0.15 \\
\hline Scenario21 & 114.28 & 1.90 & 1.77 & 4.50 & 5.93 & $-Z$ & 0.36 \\
\hline Scenario 22 & 140.45 & 2.23 & 3.14 & 4.11 & 0.51 & $-X$ & 0.74 \\
\hline Scenario23 & 179.99 & 1.52 & 2.97 & 8.04 & 5.39 & $-X$ & 1.40 \\
\hline Scenario24 & 342.73 & 3.40 & 2.47 & 7.60 & 6.01 & $-X$ & 0.59 \\
\hline Scenario 25 & 55.96 & 2.39 & 4.45 & 3.48 & 5.94 & $-Z$ & 0.46 \\
\hline Scenario26 & 94.31 & 4.76 & 4.16 & 6.51 & 5.24 & $+\mathrm{Y}$ & 3.67 \\
\hline Scenario27 & 238.34 & 4.99 & 14.10 & 4.52 & 1.28 & $+\mathrm{X}$ & 1.79 \\
\hline Scenario28 & 220.33 & 1.02 & 15.86 & 10.39 & 1.22 & $+\mathrm{Z}$ & 4.65 \\
\hline Scenario29 & 156.57 & 2.07 & 15.86 & 10.38 & 1.02 & $-Z$ & 0.69 \\
\hline Scenario30 & 317.09 & 1.72 & 15.51 & 12.13 & 1.18 & $+Z$ & 0.08 \\
\hline
\end{tabular}


Table 2 Analysis cases for grid convergence study.

\begin{tabular}{|c|c|c|c|c|c|c|}
\hline & Case 1 & Case 2 & Case 3 \\
\hline \\
KFX view
\end{tabular}


Table 3 Water deluge location index (WLI) ranking.

\begin{tabular}{|c|c|c|c|c|c|c|c|}
\hline \multicolumn{4}{|c|}{ Reference Temperature $=121^{\circ} \mathrm{C}(\mathrm{NFPA}, 1996)$} & \multicolumn{4}{|c|}{ Reference Temperature $=500^{\circ} \mathrm{C}$} \\
\hline \multicolumn{2}{|c|}{ Process - Mezzanine Deck } & \multicolumn{2}{|c|}{ Mezzanine - Upper Deck } & \multicolumn{2}{|c|}{ Process - Mezzanine Deck } & \multicolumn{2}{|c|}{ Mezzanine - Upper Deck } \\
\hline E2 & 11.110 & $\mathrm{I} 4$ & 16.882 & B4 & 2.974 & $\mathrm{H} 4$ & 3.521 \\
\hline B4 & 10.017 & $\mathrm{~J} 3$ & 16.309 & E2 & 1.974 & $\mathrm{H} 3$ & 2.828 \\
\hline $\mathrm{F} 4$ & 8.151 & $\mathrm{~J} 4$ & 16.221 & B3 & 1.267 & I4 & 2.581 \\
\hline E4 & 7.460 & $\mathrm{I} 3$ & 13.729 & B5 & 1.117 & $\mathrm{I} 3$ & 1.980 \\
\hline A4 & 6.685 & $\mathrm{I} 2$ & 11.137 & E1 & 0.825 & $\mathrm{~J} 4$ & 1.126 \\
\hline B3 & 5.939 & $\mathrm{H} 3$ & 10.261 & E4 & 0.716 & $\mathrm{I} 2$ & 1.108 \\
\hline F3 & 5.909 & $\mathrm{H} 4$ & 9.814 & A4 & 0.520 & I5 & 1.068 \\
\hline B5 & 4.957 & I5 & 8.864 & $\mathrm{C} 4$ & 0.506 & L2 & 0.914 \\
\hline E1 & 4.324 & $\mathrm{~J} 2$ & 8.727 & F4 & 0.428 & $\mathrm{~J} 1$ & 0.743 \\
\hline $\mathrm{C} 4$ & 3.487 & L2 & 7.870 & $\mathrm{C} 5$ & 0.270 & J5 & 0.714 \\
\hline E3 & 3.409 & I1 & 6.097 & B2 & 0.224 & G4 & 0.708 \\
\hline C5 & 3.150 & J5 & 5.793 & C3 & 0.222 & $\mathrm{~K} 2$ & 0.687 \\
\hline $\mathrm{F} 2$ & 2.979 & $\mathrm{~J} 1$ & 5.366 & $\mathrm{~F} 2$ & 0.212 & $\mathrm{~J} 2$ & 0.664 \\
\hline A5 & 2.612 & $\mathrm{~K} 4$ & 5.323 & A3 & 0.212 & $\mathrm{~J} 3$ & 0.627 \\
\hline $\mathrm{C} 3$ & 2.227 & L3 & 5.229 & E5 & 0.197 & I1 & 0.560 \\
\hline E5 & 2.096 & $\mathrm{~K} 2$ & 5.193 & F1 & 0.156 & K4 & 0.462 \\
\hline B2 & 2.056 & $\mathrm{~K} 3$ & 4.809 & E3 & 0.137 & H5 & 0.444 \\
\hline A3 & 2.025 & $\mathrm{H} 2$ & 4.292 & A5 & 0.121 & $\mathrm{H} 2$ & 0.396 \\
\hline $\mathrm{C} 2$ & 1.840 & G4 & 3.865 & $\mathrm{C} 2$ & 0.116 & G3 & 0.352 \\
\hline D1 & 1.770 & H5 & 3.740 & F3 & 0.111 & L1 & 0.313 \\
\hline $\mathrm{F} 1$ & 1.463 & G3 & 3.292 & D5 & 0.023 & $\mathrm{~K} 1$ & 0.310 \\
\hline D4 & 1.118 & K1 & 3.214 & D4 & 0.023 & $\mathrm{G} 2$ & 0.224 \\
\hline D5 & 0.910 & L4 & 3.051 & D2 & 0.004 & L3 & 0.219 \\
\hline D2 & 0.856 & K5 & 3.011 & $\mathrm{C} 1$ & 0.003 & $\mathrm{~J} 1$ & 0.201 \\
\hline $\mathrm{C} 1$ & 0.850 & L1 & 2.899 & D1 & 0.003 & K5 & 0.167 \\
\hline $\mathrm{A} 2$ & 0.801 & G5 & 2.871 & B1 & 0.001 & $\mathrm{H} 1$ & 0.162 \\
\hline B1 & 0.780 & H1 & 1.200 & A1 & 0.000 & $\mathrm{~L} 4$ & 0.127 \\
\hline D3 & 0.642 & $\mathrm{G} 2$ & 1.000 & A5 & 0.000 & G5 & 0.012 \\
\hline F5 & 0.547 & L5 & 0.620 & D3 & 0.000 & G1 & 0.009 \\
\hline A1 & 0.137 & G1 & 0.223 & F5 & 0.000 & L5 & 0.000 \\
\hline
\end{tabular}


Table 4 Proposed positions for nine water deluge systems, as optimised by the WLI.

\begin{tabular}{|c|c|c|c|c|c|c|c|}
\hline \multicolumn{4}{|c|}{ Reference Temperature $=\mathbf{1 2 1}^{\circ} \mathbf{C}(\mathbf{N F P A}, \mathbf{1 9 9 6})$} & \multicolumn{5}{c|}{ Reference Temperature $=\mathbf{5 0 0}^{\circ} \mathbf{C}$} \\
\hline Process - Mezzanine Deck & \multicolumn{2}{|c|}{ Mezzanine - Upper Deck } & Process - Mezzanine Deck & \multicolumn{2}{|c|}{ Mezzanine - Upper Deck } \\
\hline E2 & 11.11012 & I4 & 16.88203 & B4 & 2.97427 & H4 & 3.520935 \\
\hline B4 & 10.01698 & J3 & 16.30889 & E2 & 1.974124 & H3 & 2.828089 \\
\hline F4 & 8.151248 & J4 & 16.22076 & B3 & 1.267151 & I4 & 2.580729 \\
\hline E4 & 7.460242 & I3 & 13.72904 & B5 & 1.117374 & I3 & 1.980452 \\
\hline A4 & 6.685275 & I2 & 11.13692 & E1 & 0.8248 & J4 & 1.126065 \\
\hline B3 & 5.938911 & H3 & 10.2607 & E4 & 0.715505 & I2 & 1.107799 \\
\hline F3 & 5.908954 & H4 & 9.814175 & A4 & 0.519903 & I5 & 1.068328 \\
\hline B5 & 4.956885 & I5 & 8.86384 & C4 & 0.506181 & L2 & 0.913737 \\
\hline E1 & 4.323762 & J2 & 8.727307 & F4 & 0.428297 & J1 & 0.743403 \\
\hline
\end{tabular}

Table 5 Size of heated areas at 40 s related to critical temperatures $\left(\mathrm{m}^{2}\right)$.

\begin{tabular}{|c|c|c|c|}
\hline Temperature $\left({ }^{\circ} \mathbf{C}\right)$ & $\begin{array}{c}\text { Without water } \\
\text { deluge }\end{array}$ & $\begin{array}{c}\text { With water deluge } \\
\text { (by uniform arrangement) }\end{array}$ & $\begin{array}{c}\text { With water deluge } \\
\text { (by WLI) }\end{array}$ \\
\hline Below 127 (Safe) & $67.2(7)$ & $220.8(23)$ & $297.6(31)$ \\
\hline $\begin{array}{c}127-203 \\
\text { (Affecting human) }\end{array}$ & $57.6(6)$ & $124.8(13)$ & $76.8(8)$ \\
\hline $203-400$ & $96.0(10)$ & $134.4(14)$ & $105.6(11)$ \\
\hline $\begin{array}{c}400-450 \\
\text { (Affecting structures) }\end{array}$ & $9.6(1)$ & $19.2(2)$ & $19.2(2)$ \\
\hline $450-700$ & $115.2(12)$ & $19.2(2)$ & $67.2(7)$ \\
\hline $\begin{array}{c}\text { Above 700 } \\
\text { (Melting point of steel) }\end{array}$ & $230.4(24)$ & $57.6(6)$ & $9.6(1)$ \\
\hline Total & $576.0(60)$ & $576.0(60)$ & $576.0(60)$ \\
\hline
\end{tabular}



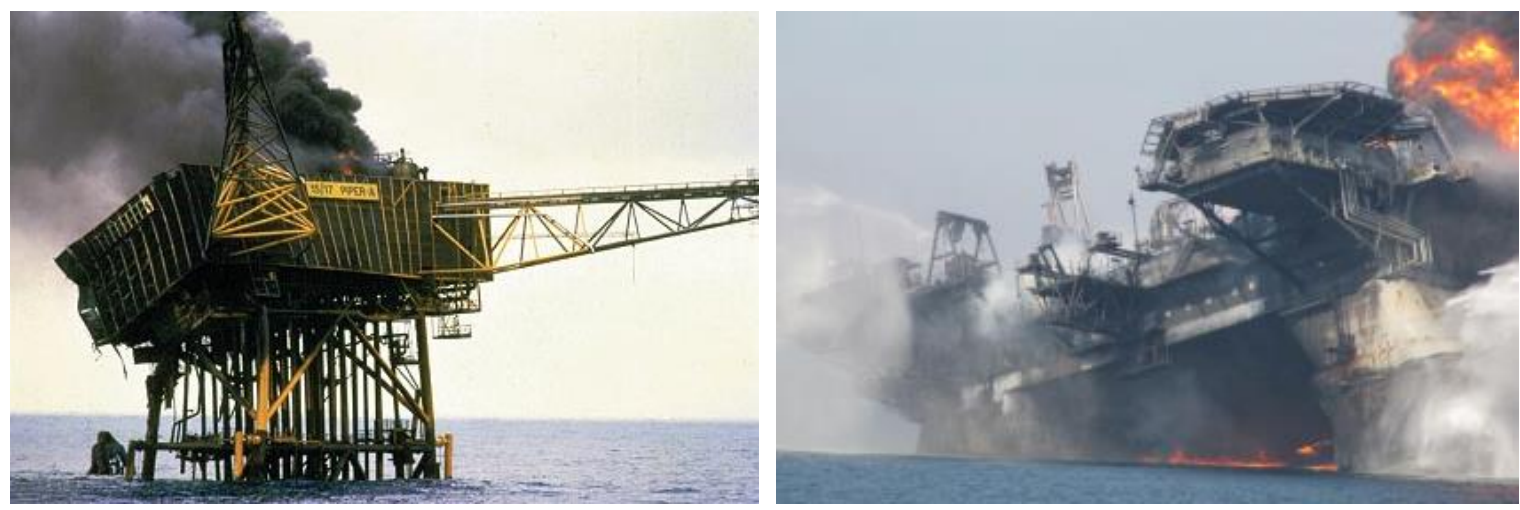

Fig. 1. Piper Alpha (6 July 1988, North Sea, left) and Deepwater Horizon (20 April 2010, Gulf of Mexico, right) accidents.

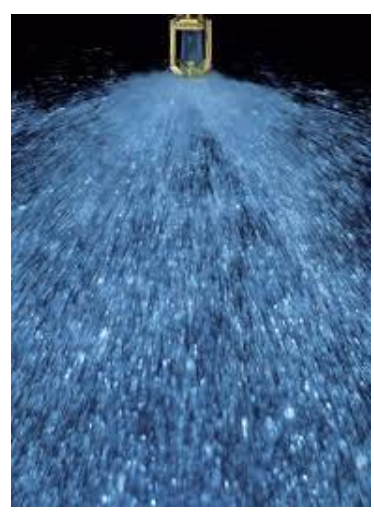

(a) Water deluge system

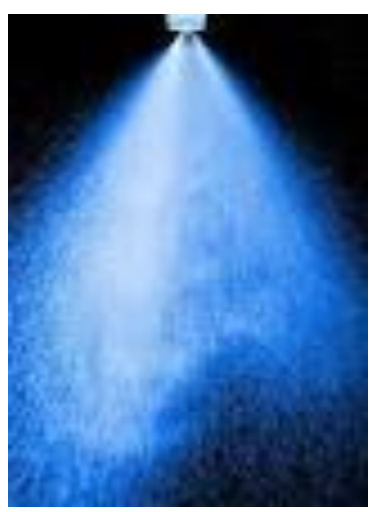

(b) Water mist system

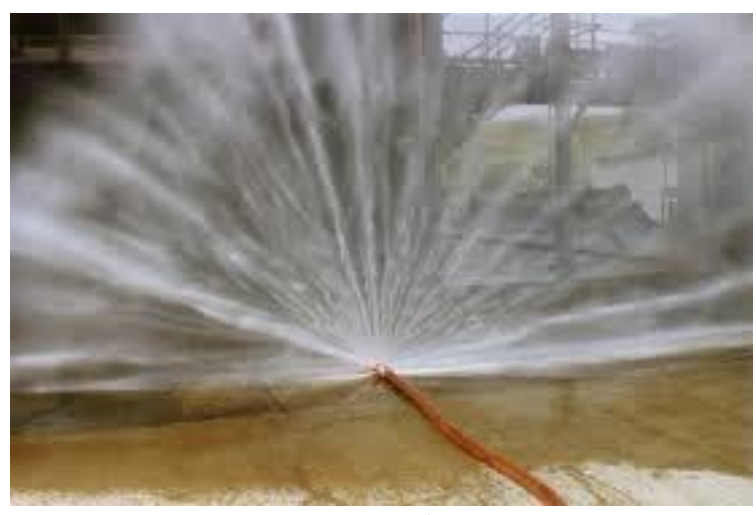

(c) Water curtain system

Fig. 2. Types of water spray systems. 


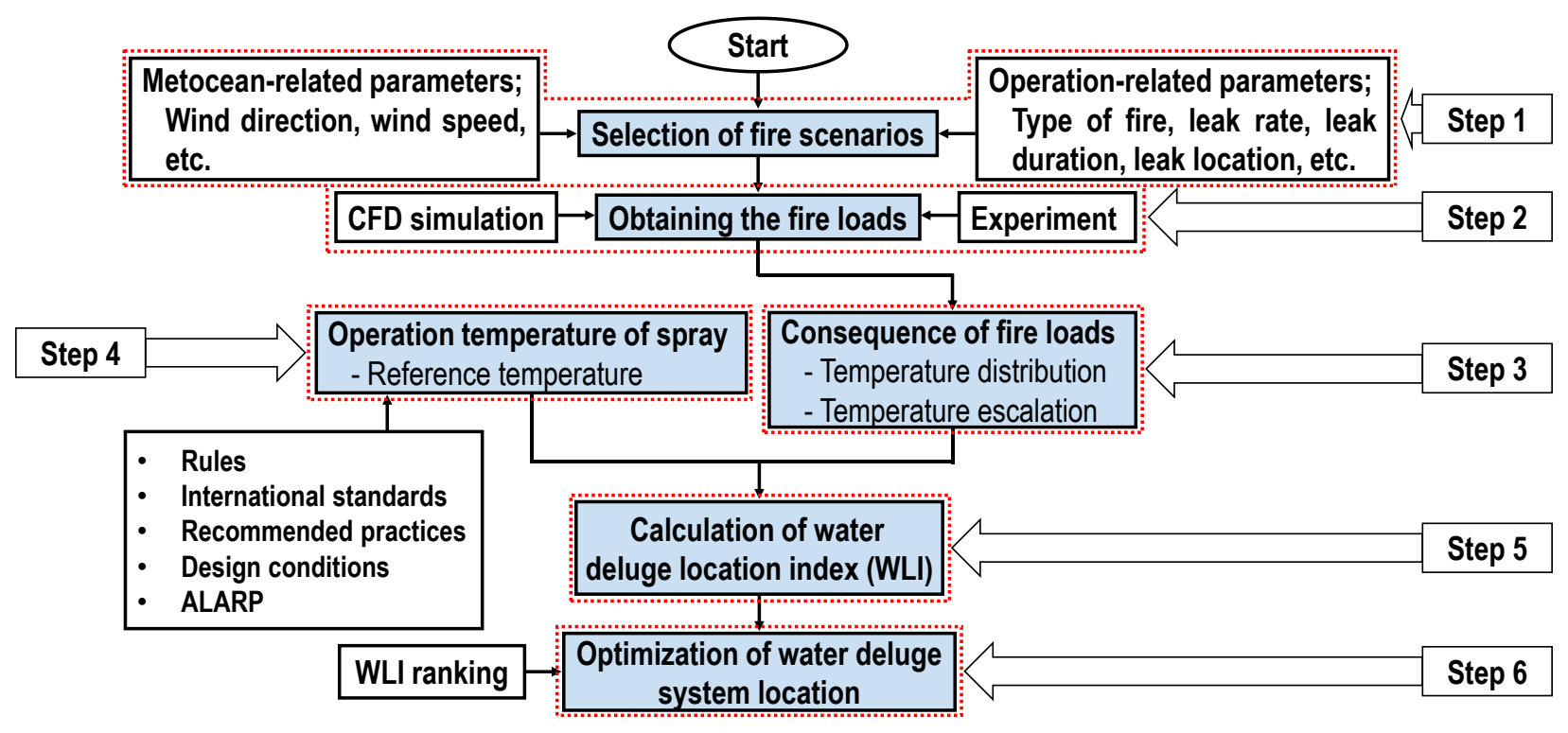

Fig. 3. Proposed procedure for the optimisation of water deluge system locations using the WLI.

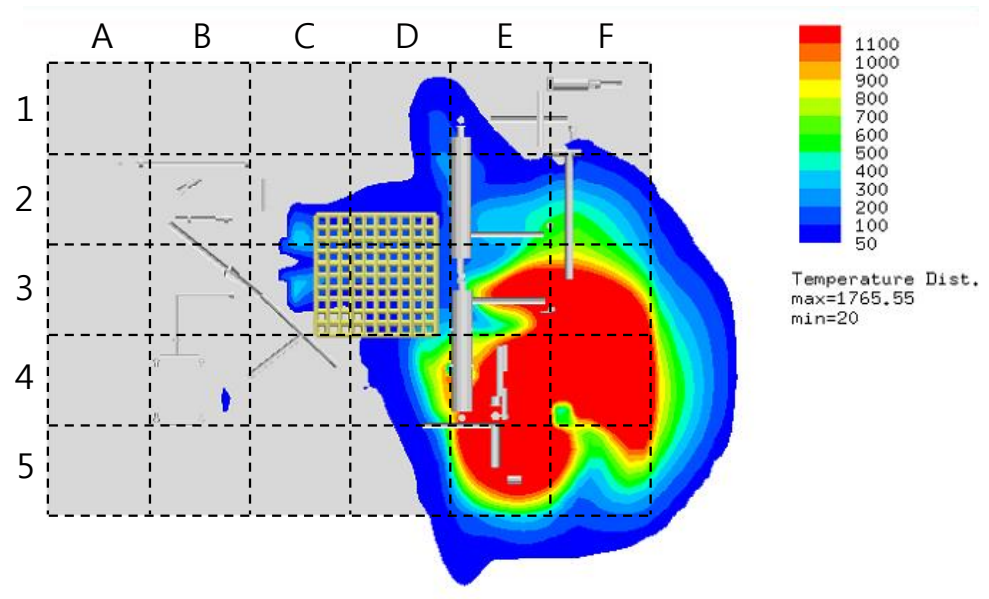

Fig. 4. An example of temperature distributions at specific times obtained by fire CFD simulation with spaces for calculating the WLI. 


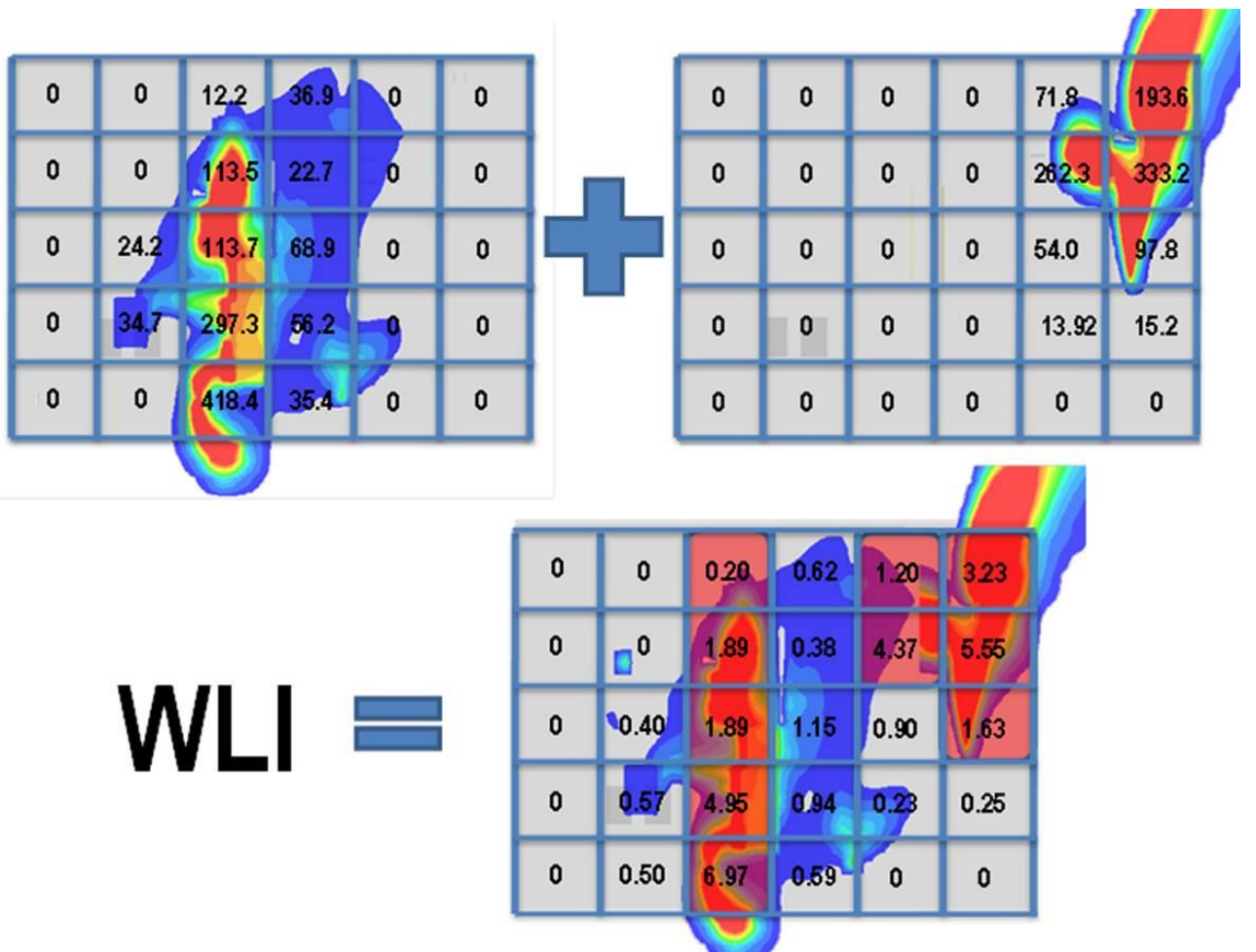

Fig. 5. An example of nine WLI-optimised water deluge system locations with two fire scenarios.

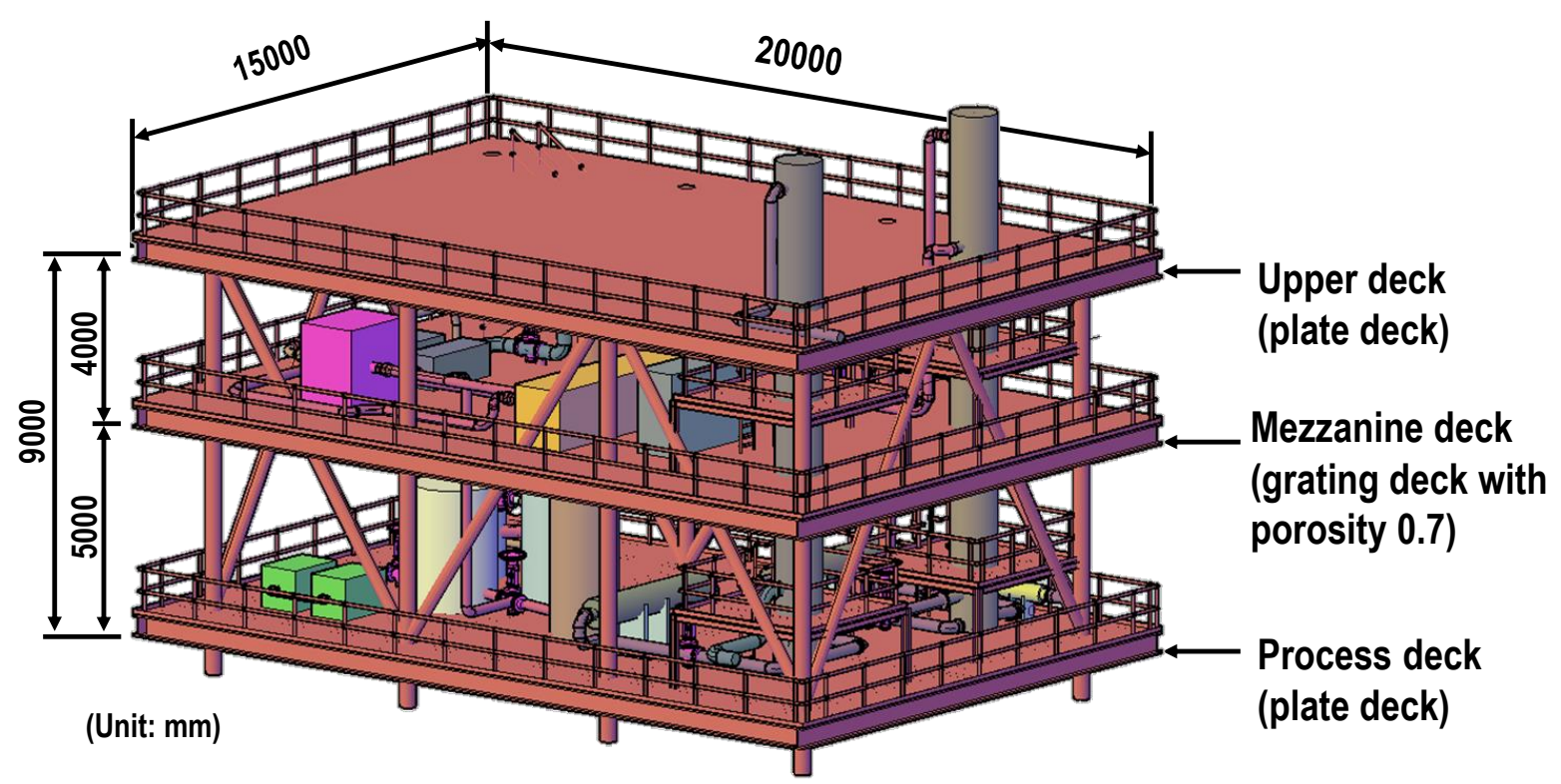

Fig. 6. The target structure (hypothetical FLNG topside module developed by KOSORI). 

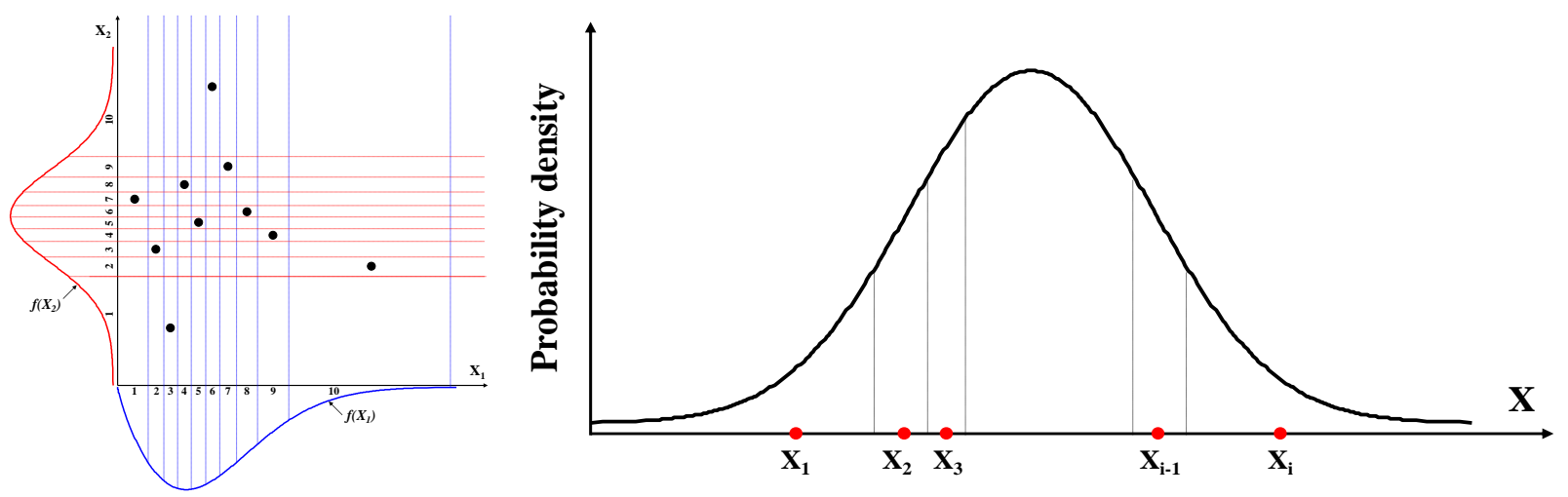

Fig. 7. Schematic of Latin hypercube sampling (LHS) technique. 


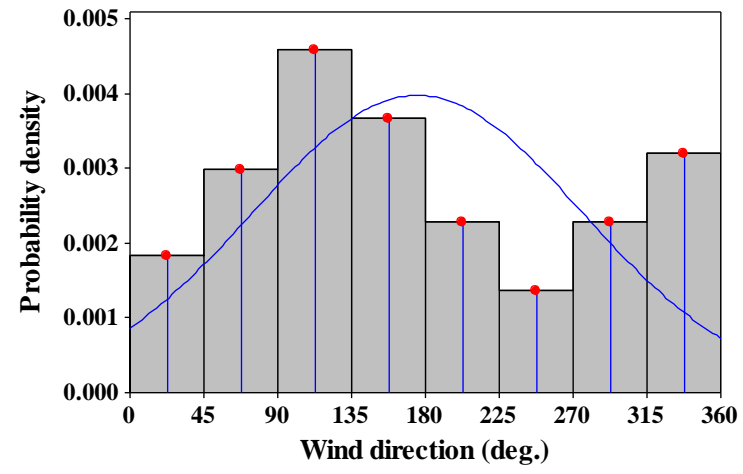

(a) Wind direction

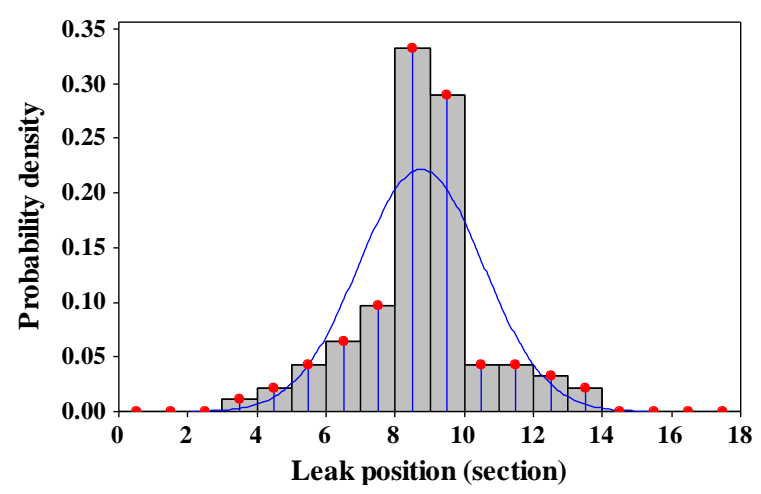

(c) Leak position

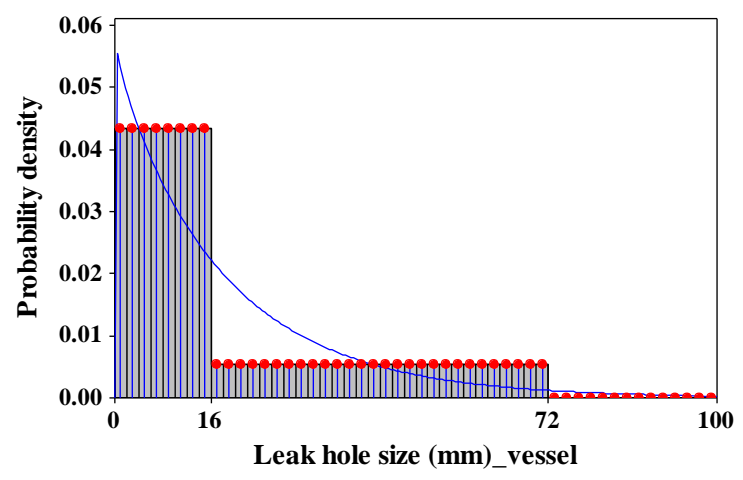

(e) Leak hole size of vessels

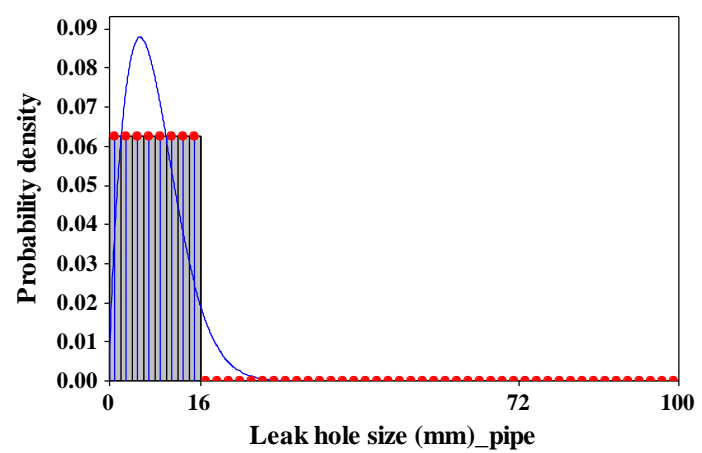

(g) Leak hole size of pipes

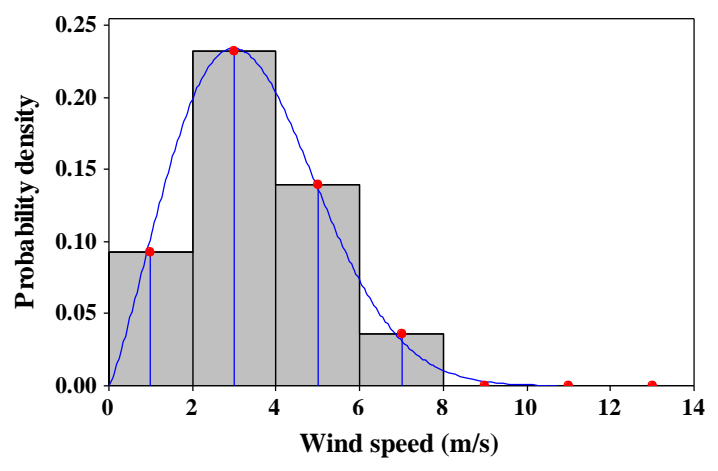

(b) Wind speed

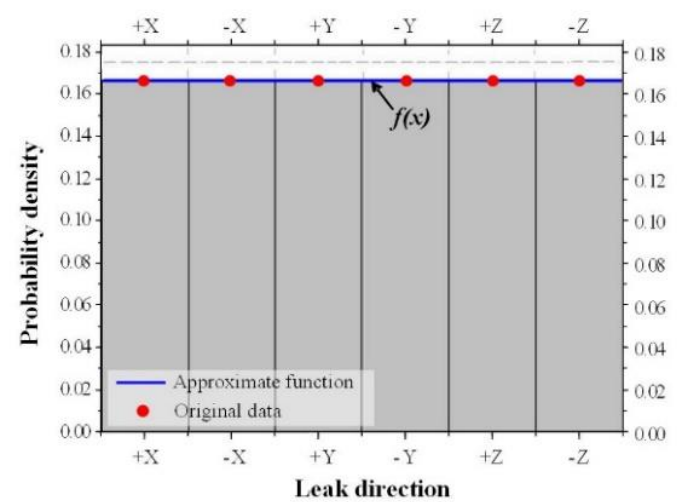

(d) Leak direction

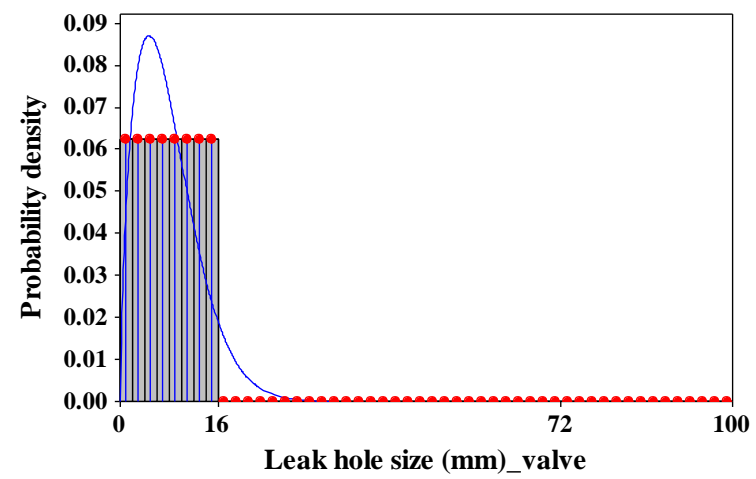

(f) Leak hole size of valves

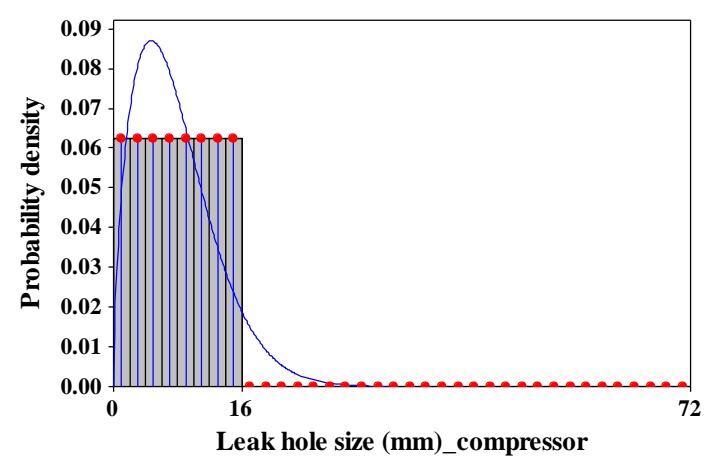

(h) Leak hole size of compressors

Fig. 8. Probability density function of each parameter. 

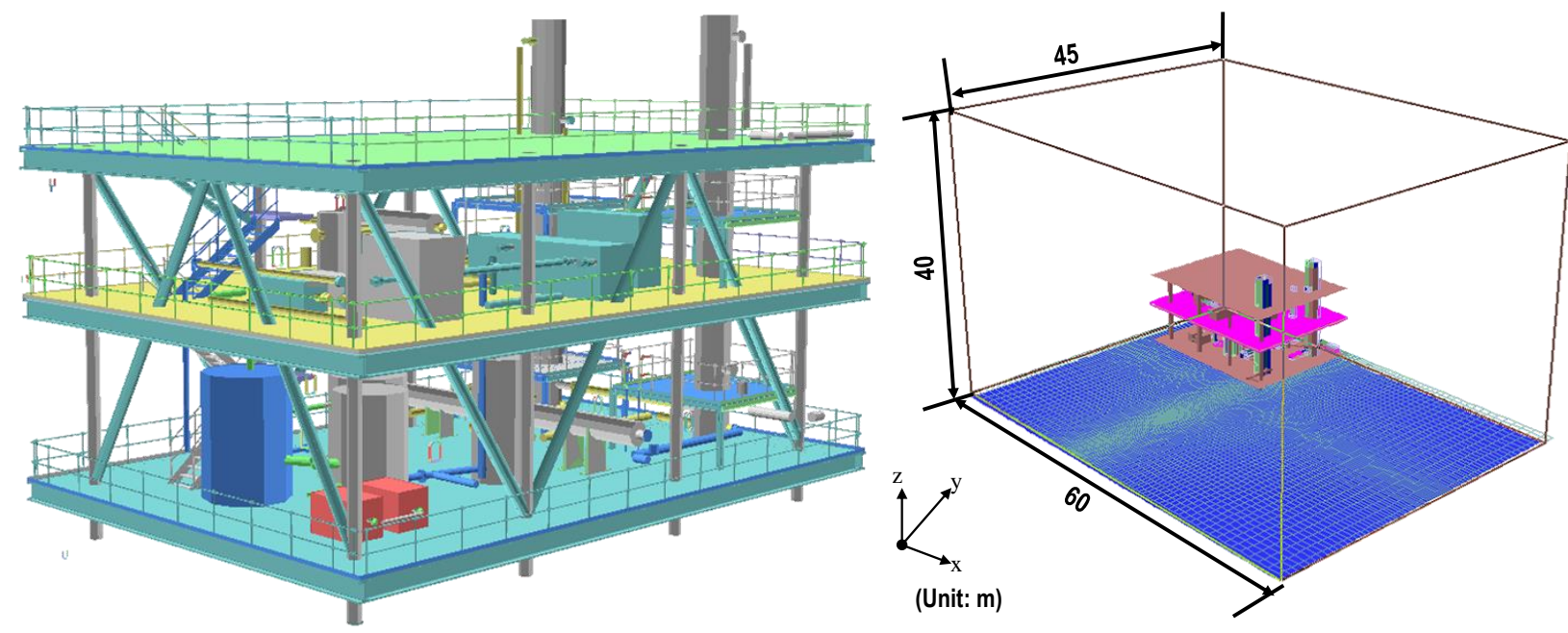

Fig. 9. Target structure modelled in KFX CFD simulation (left) and simulation volume (right).

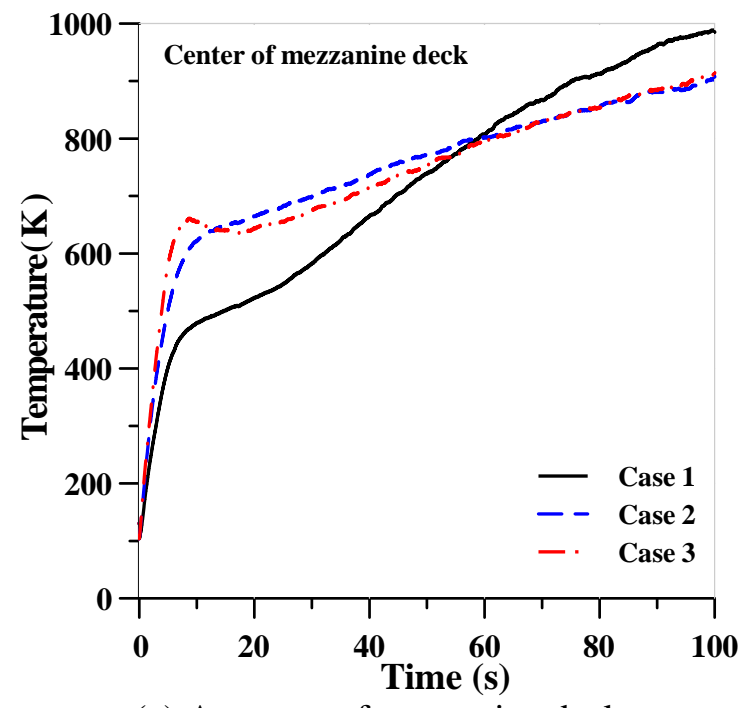

(a) At centre of mezzanine deck

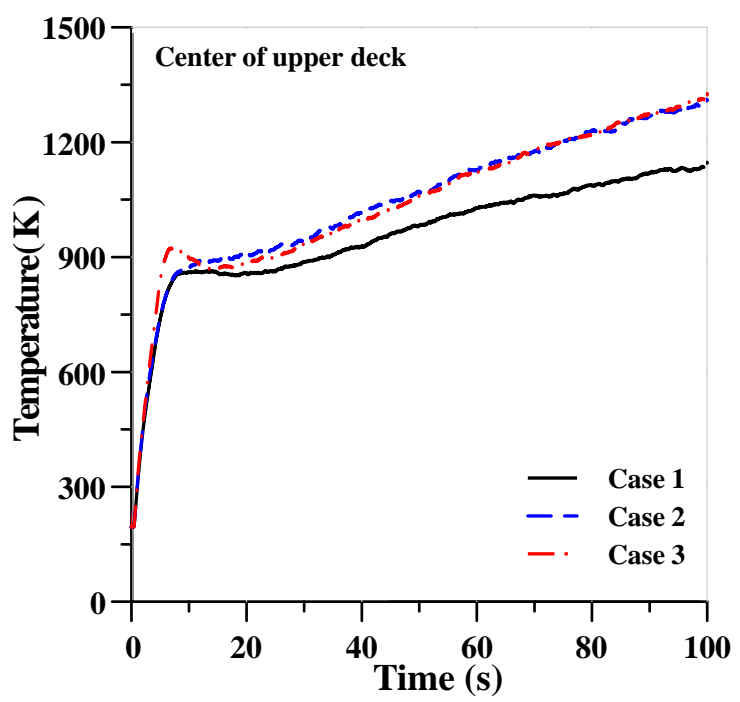

(b) At centre of process deck

Fig. 10. Results of the grid convergence study. 


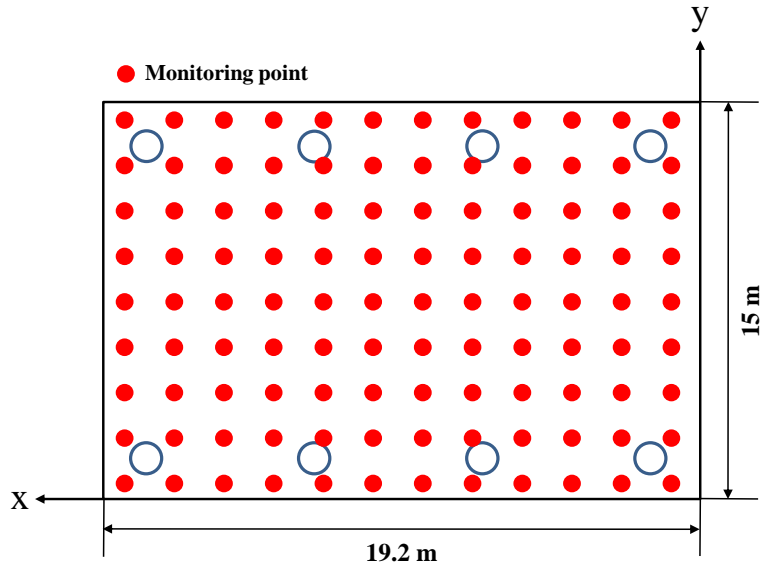

(a) Monitoring points at each elevation

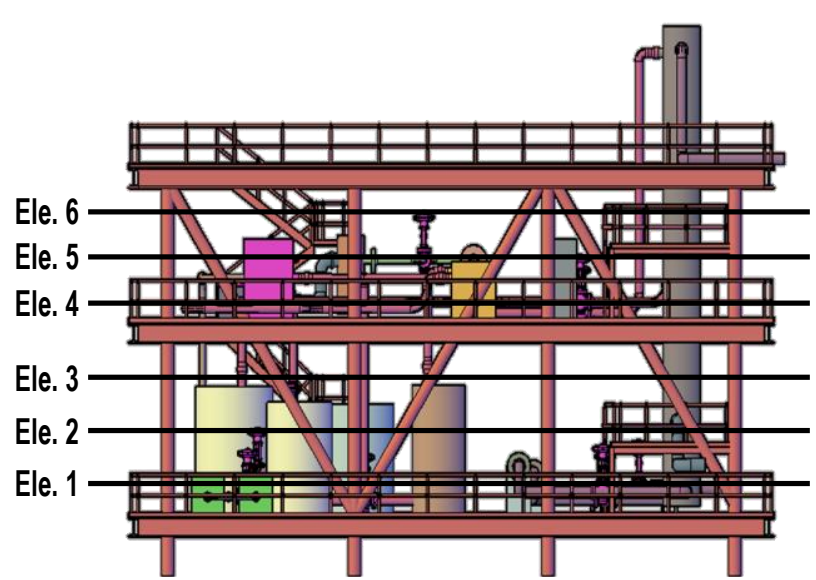

(b) Elevation levels

Fig. 11. Monitoring points to obtain the fire loads.

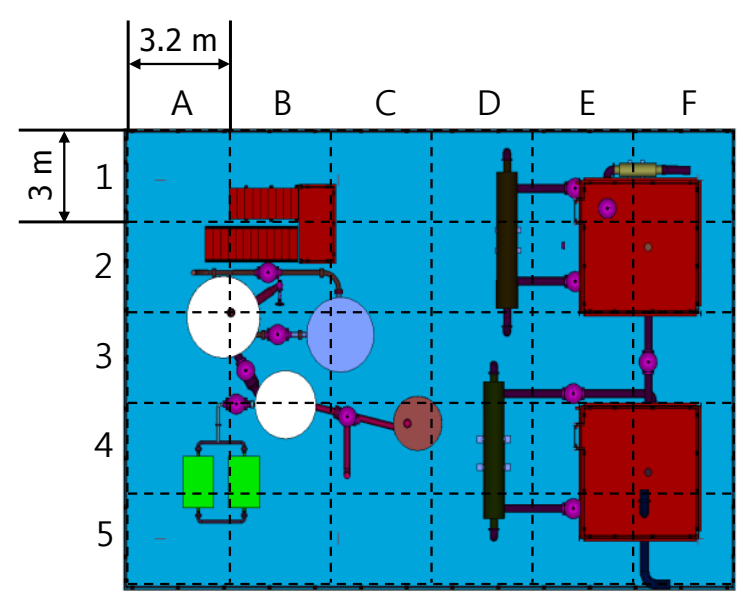

(a) Between process and mezzanine decks

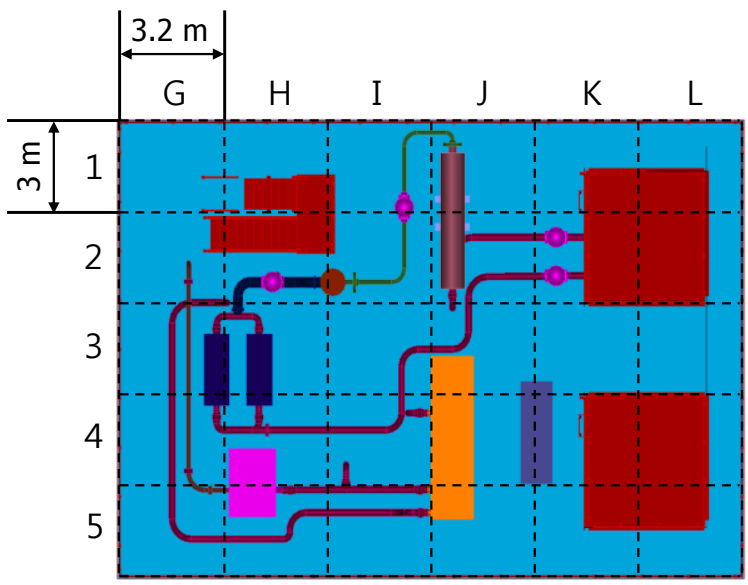

(b) Between mezzanine and upper decks

Fig. 12. Divided areas for WLI calculation. 


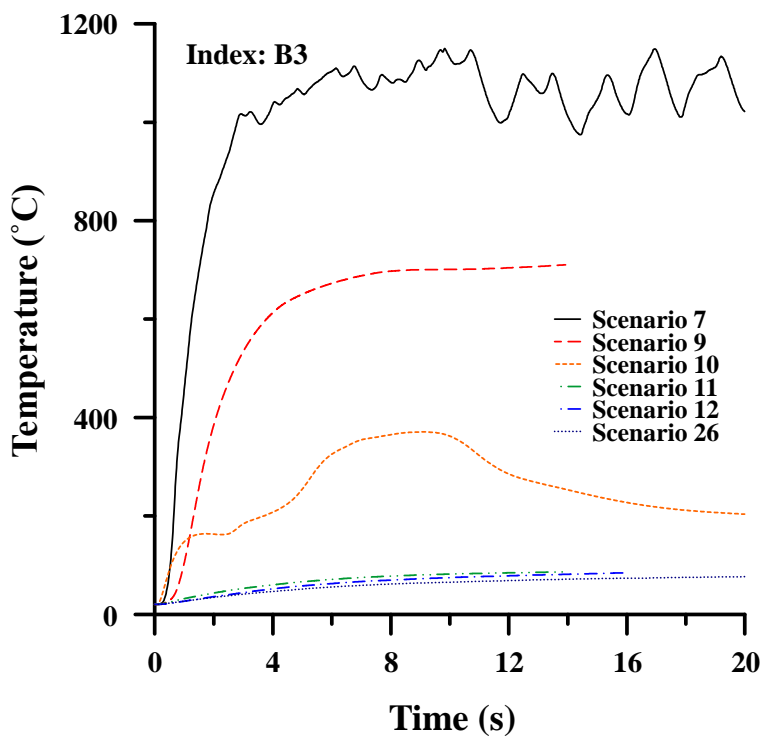

(a) Space: B3

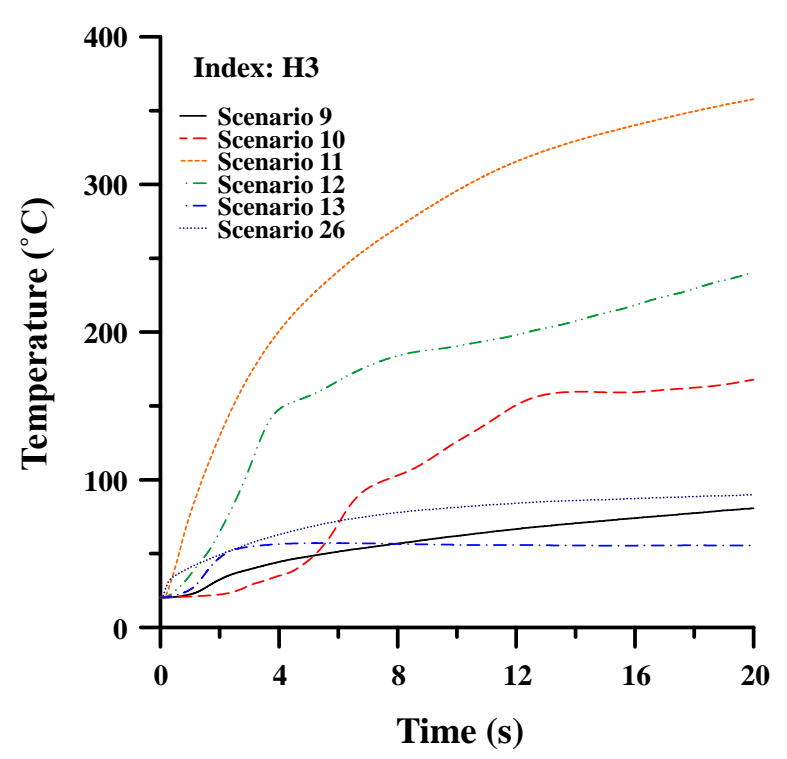

(b) Space: H3

Fig. 13. Examples of the simulation results for each space.

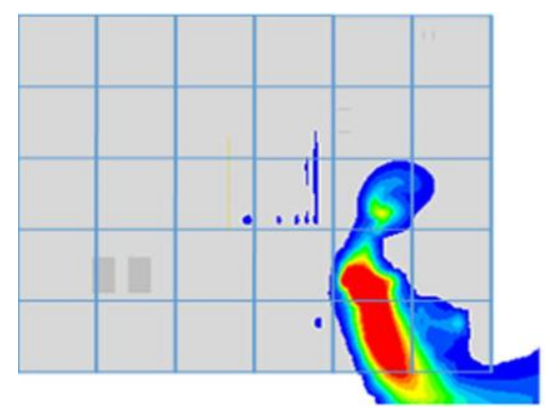

(a) Scenario 1

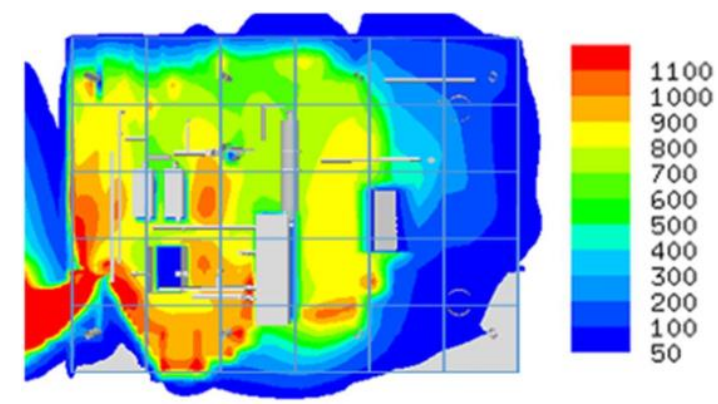

(c) Scenario 21

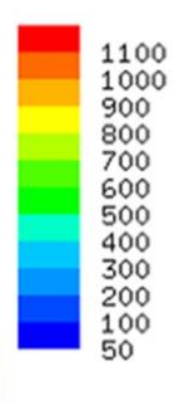

(1)

1100
1000
900
800
700
600
500
400
300
200
100
50
Fig. 14. Examples of temperature distributions at $40 \mathrm{~s}$ and $2 \mathrm{~m}$ of elevation level $\left({ }^{\circ} \mathrm{C}\right)$. 


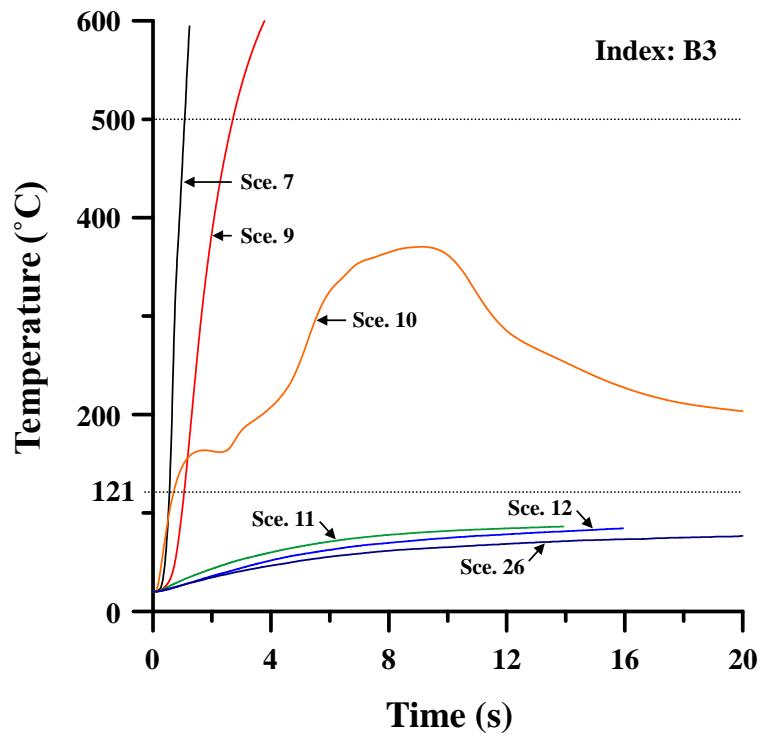

(a) Space: B3

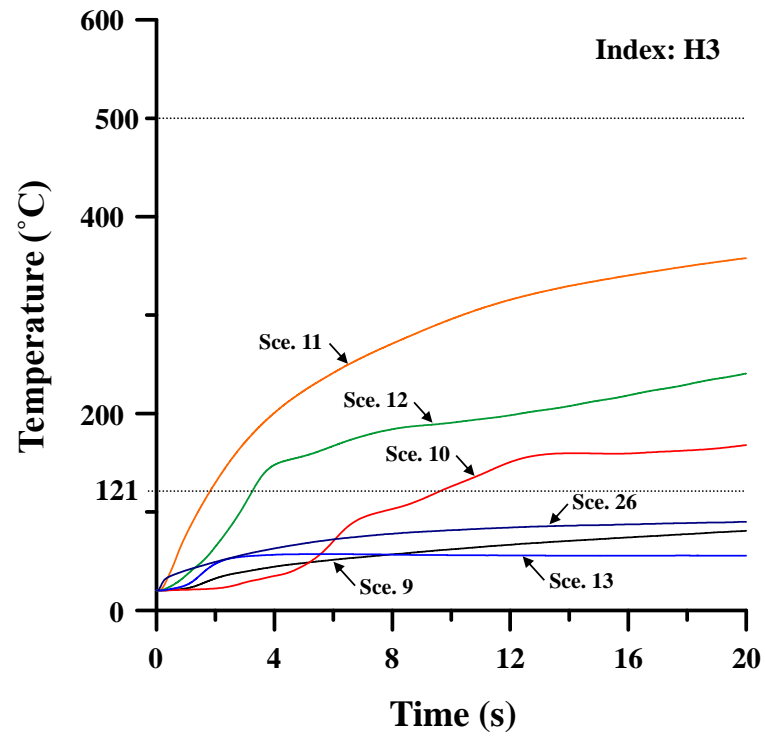

(c) Space: $\mathrm{H} 3$

Fig. 15. Examples of temperature-time histories for each space with reference temperatures $\left(121^{\circ} \mathrm{C}\right.$ and $\left.500^{\circ} \mathrm{C}\right)$.

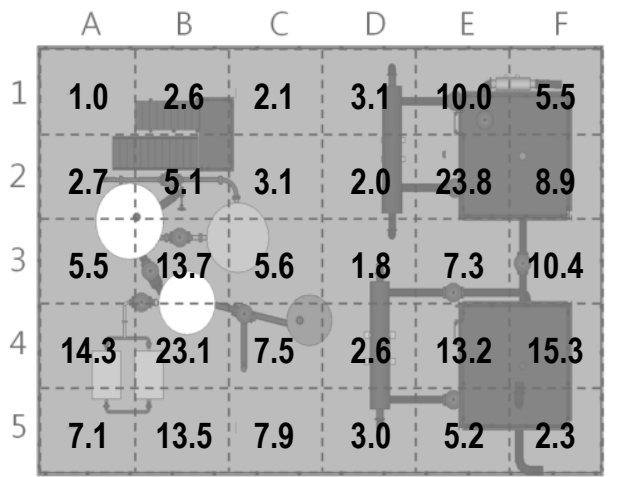

(a) Between process and mezzanine decks

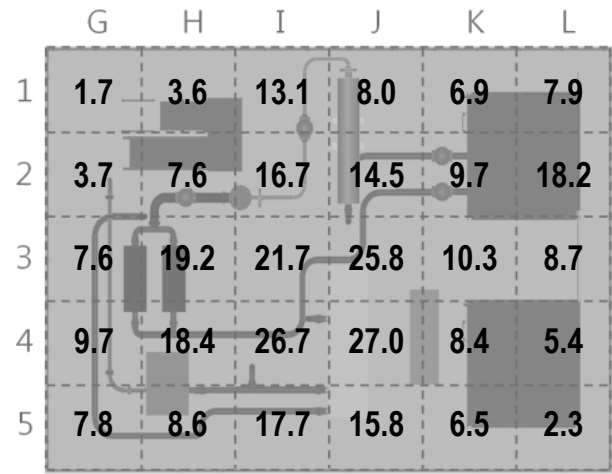

(b) Between mezzanine and upper decks

Fig. 16. Average slope of the temperature-time history up to the reference temperature for each space, considering all scenarios (reference temperature $=121^{\circ} \mathrm{C}$ ). 


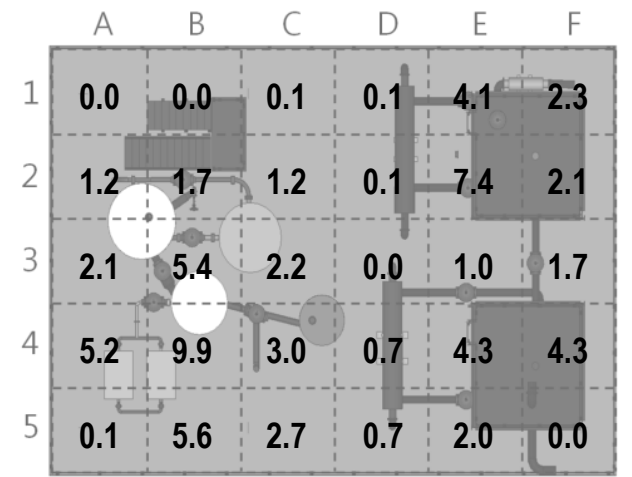

(a) Between process and mezzanine decks

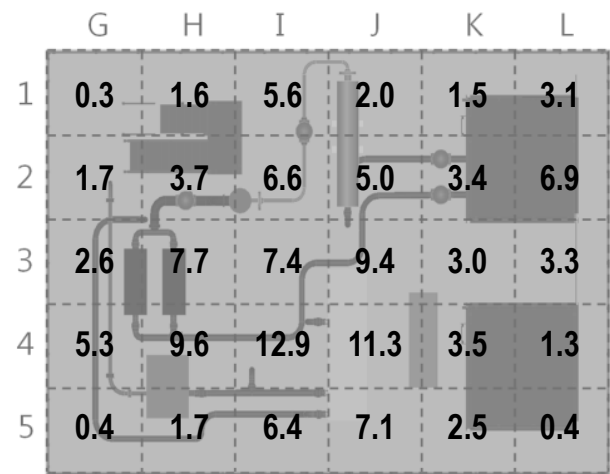

(b) Between mezzanine and upper decks

Fig. 17. Average slope of the temperature-time history up to the reference temperature for each space, considering all scenarios (reference temperature $=500^{\circ} \mathrm{C}$ ).

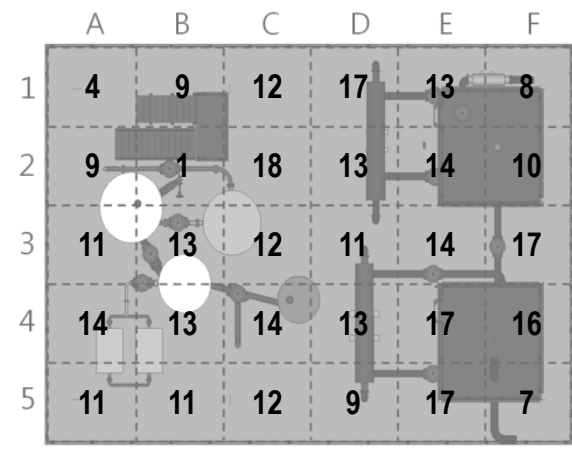

(a) Between process and mezzanine decks

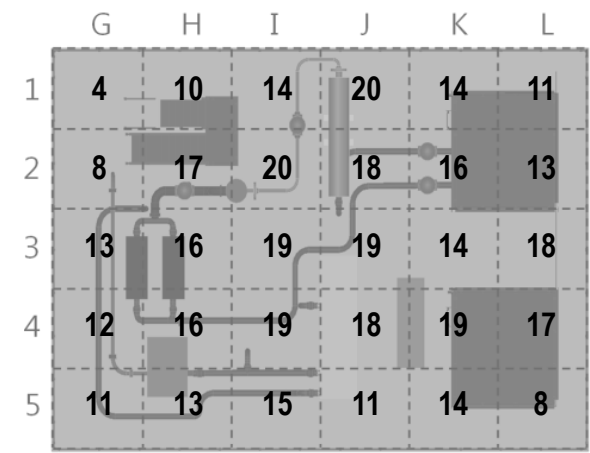

(b) Between mezzanine and upper decks

Fig. 18. Frequencies $(F)$ that detect the reference temperature for each space, considering all scenarios (reference temperature $=121^{\circ} \mathrm{C}$ ).

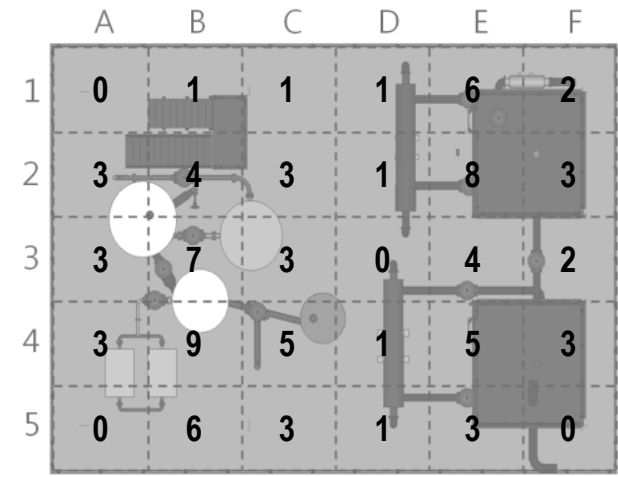

(a) Between process and mezzanine decks

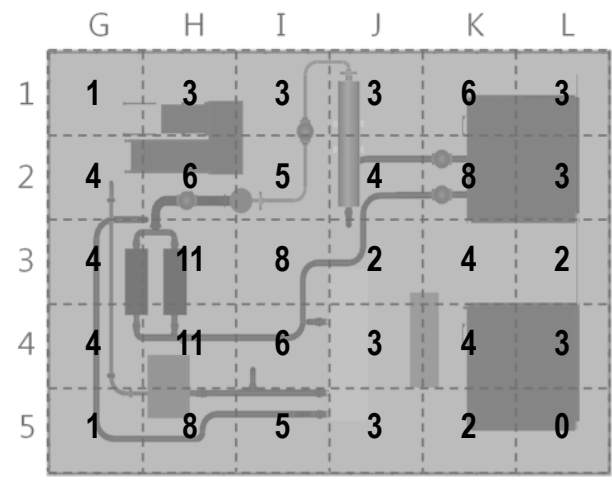

(b) Between mezzanine and upper decks

Fig. 19. Frequencies $(F)$ that detect the reference temperature for each space, considering all scenarios (reference temperature $=500^{\circ} \mathrm{C}$ ). 


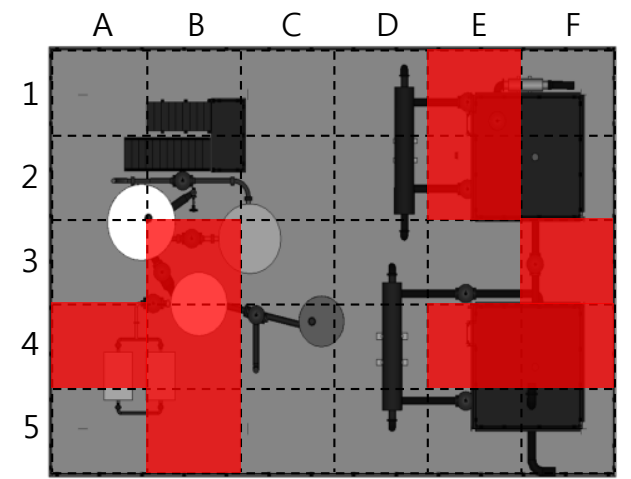

(a) Between process and mezzanine decks

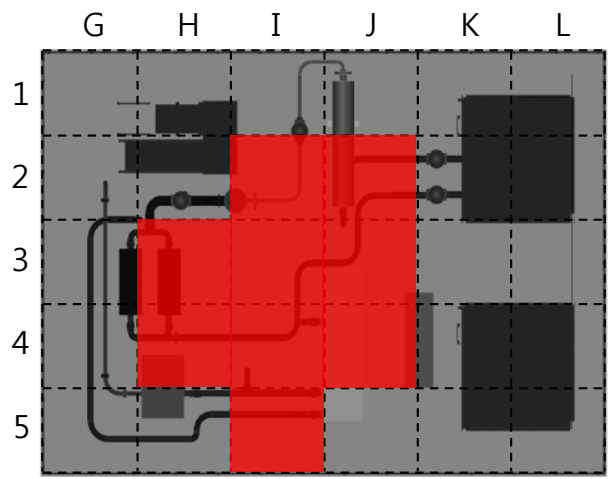

(b) Between mezzanine and upper decks

Fig. 20. Nine high-ranking locations by WLI (reference temperature $=121^{\circ} \mathrm{C}$ ).

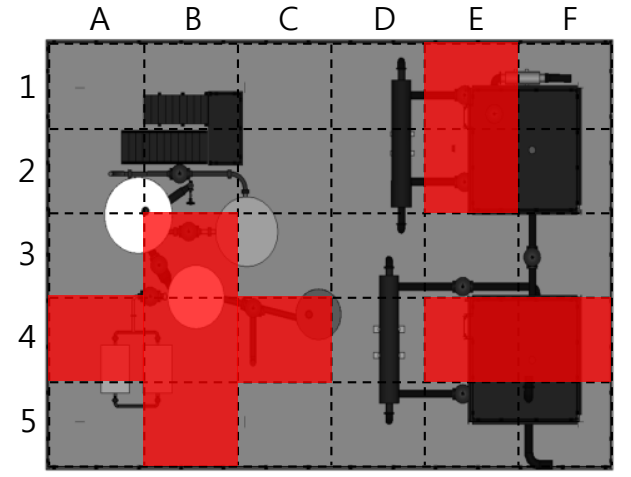

(a) Between process and mezzanine decks

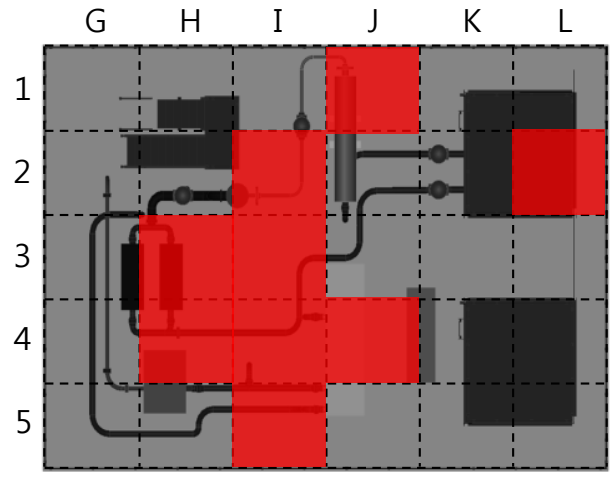

(b) Between mezzanine and upper decks

Fig. 21. Nine high-ranking locations according to the WLI (reference temperature $=500^{\circ} \mathrm{C}$ ).

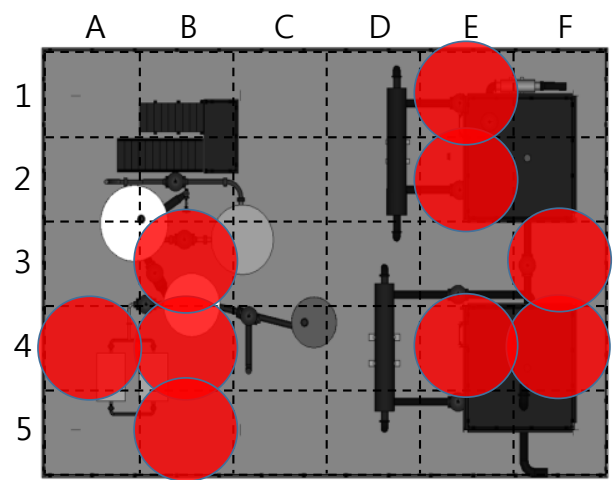

(a) Between process and mezzanine decks

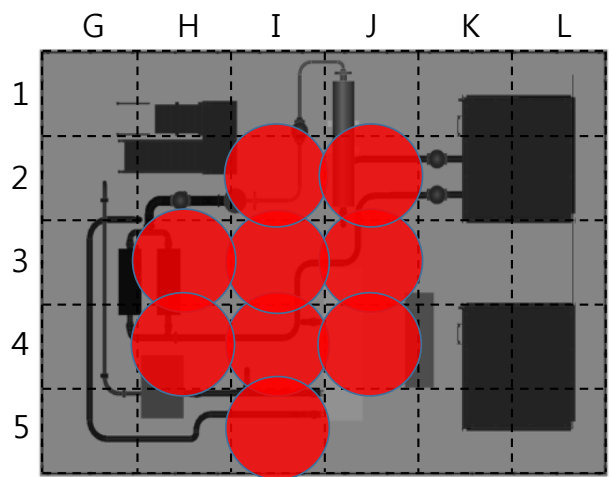

(b) Between mezzanine and upper decks

Fig. 22. WLI-optimised water deluge system locations. 


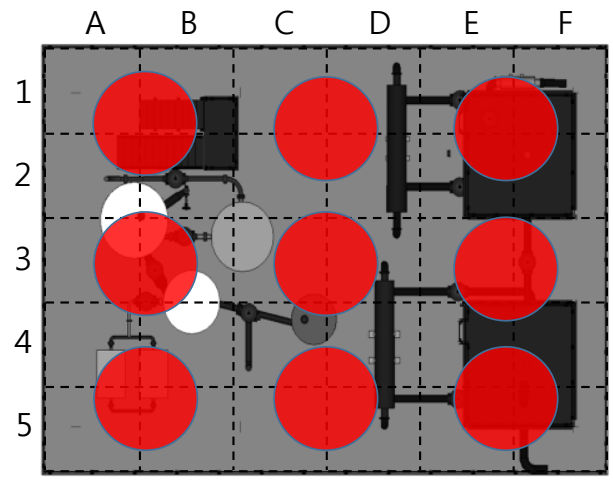

(a) Between process and mezzanine decks

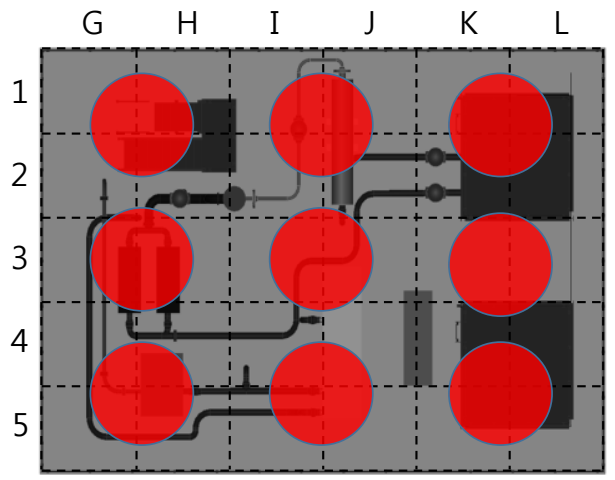

(b) Between mezzanine and upper decks

Fig. 23. Water deluge system locations according to the uniform arrangement method.

Right: Between process and mezzanine decks
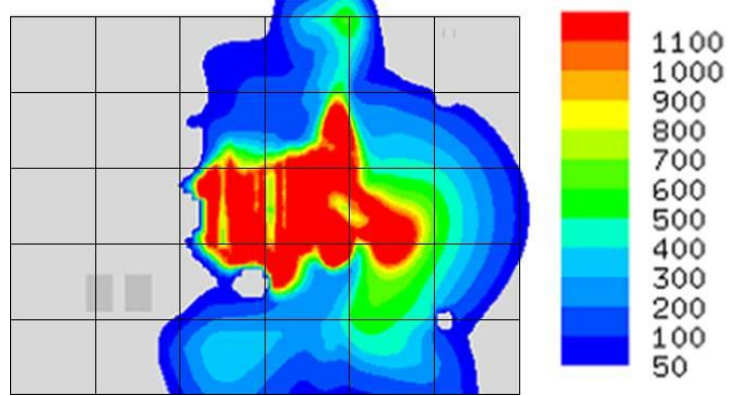

Left: Between mezzanine and upper decks
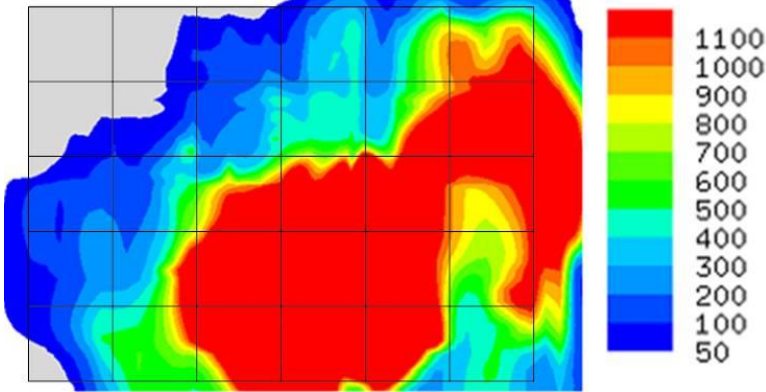

(a) Without water deluge system
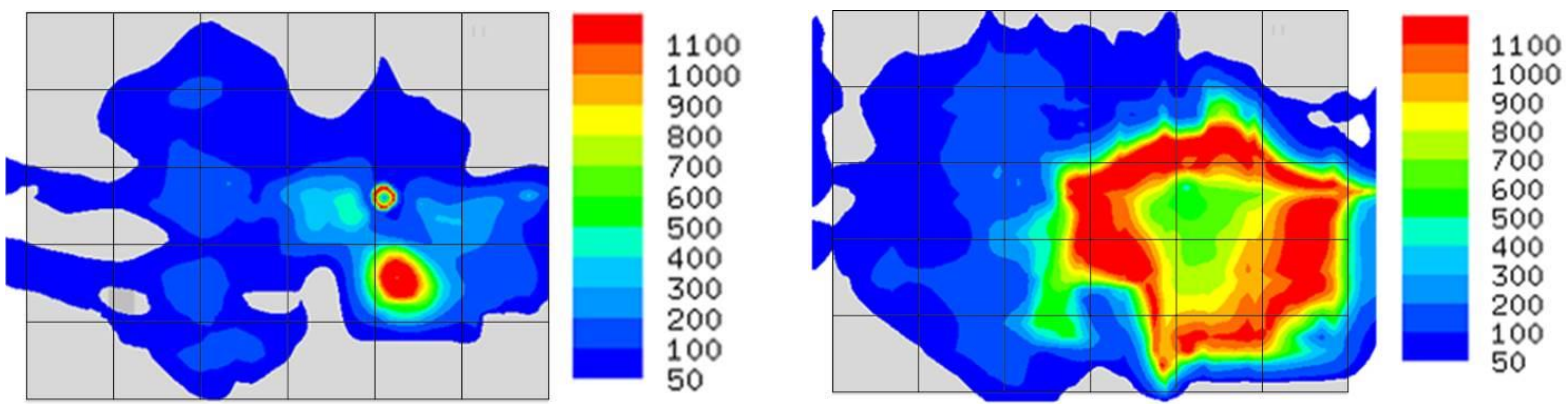

(b) With uniformly distributed water deluge systems
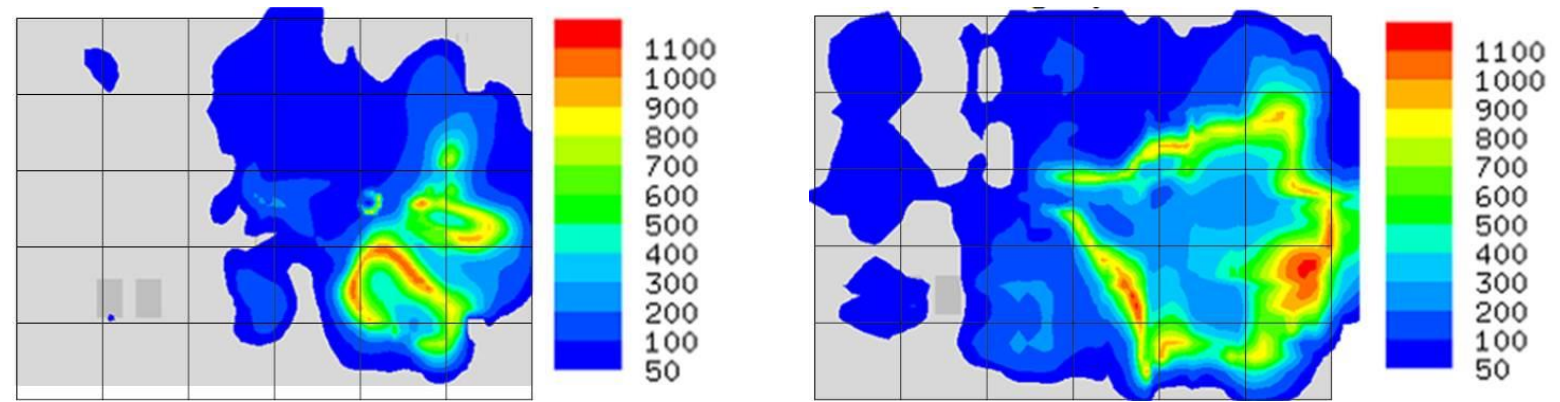

(c) With WLI-optimised water deluge systems

Fig. 24. Comparison of temperature distributions $60 \mathrm{~s}$ after ignition, without and with water deluge systems $\left({ }^{\circ} \mathrm{C}\right)$. 


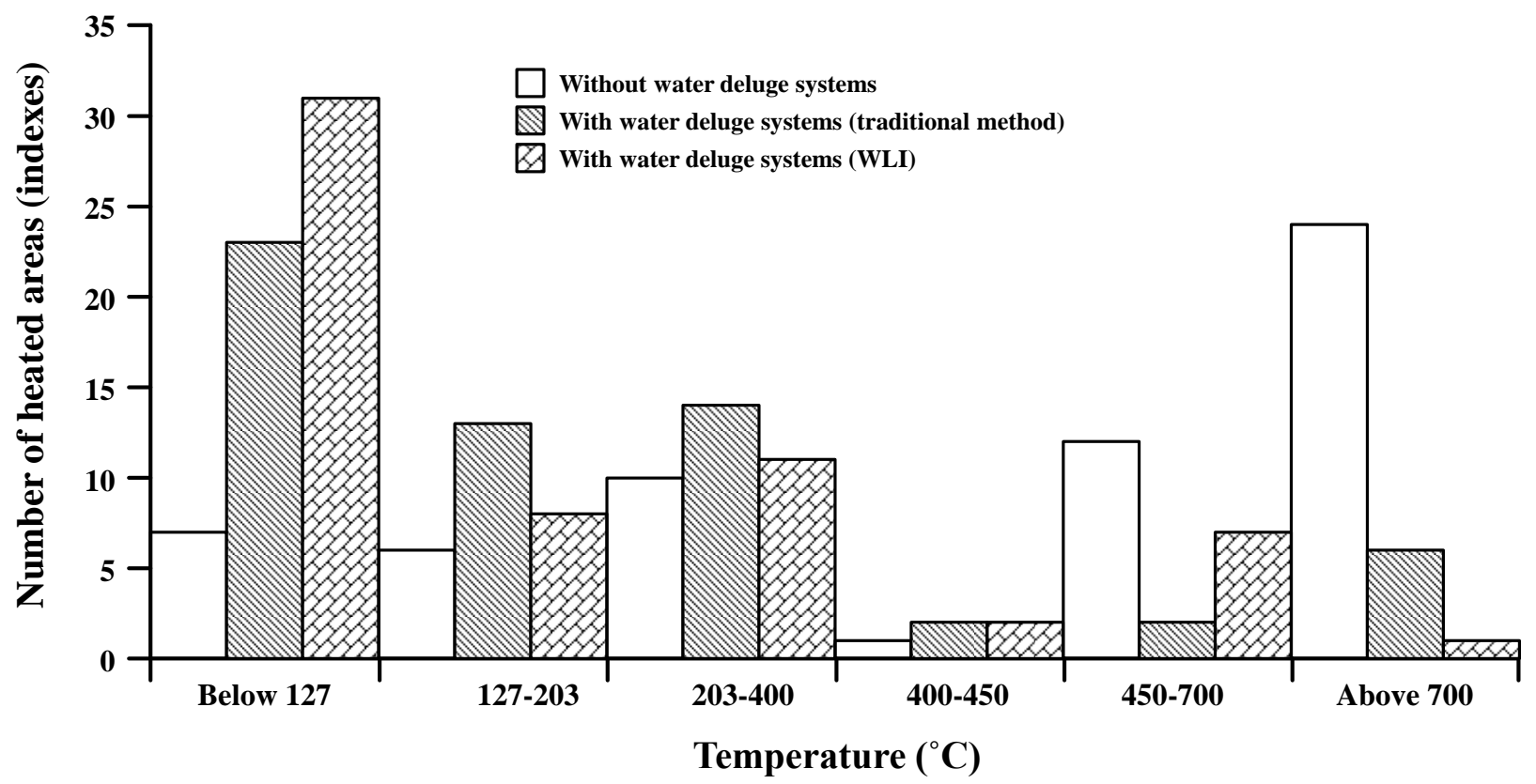

Fig. 25. Effects of water sprays on the number of heated areas.

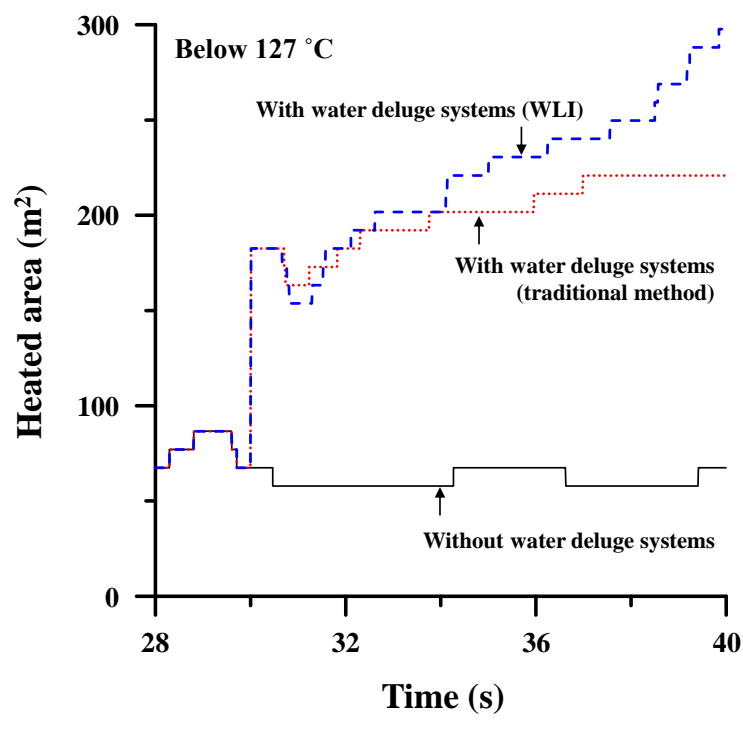

(a) Below $127^{\circ} \mathrm{C}$

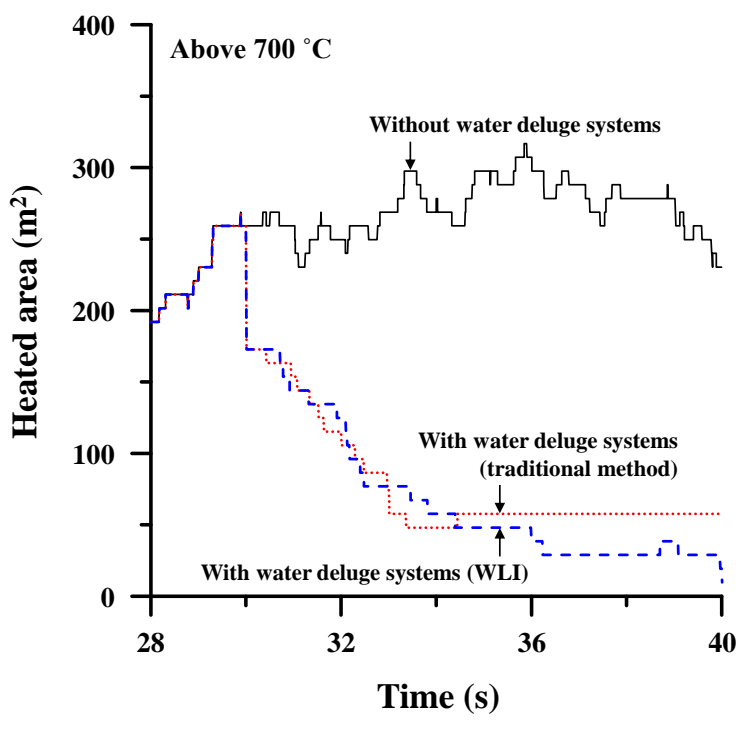

(b) Above $700^{\circ} \mathrm{C}$

Fig. 26. Comparison of time dependent heated area, without and with water deluge systems. 